\title{
The stable isotopic composition of water vapour above Corsica during the HyMeX SOP1 campaign: insight into vertical mixing processes from lower-tropospheric survey flights
}

\author{
Harald Sodemann ${ }^{1,2,3}$, Franziska Aemisegger ${ }^{3}$, Stephan Pfahl ${ }^{3}$, Mark Bitter ${ }^{4}$, Ulrich Corsmeier ${ }^{5}$, Thomas Feuerle ${ }^{4}$, \\ Pascal Graf $^{3}$, Rolf Hankers ${ }^{4}$, Gregor Hsiao ${ }^{6, a}$, Helmut Schulz ${ }^{4}$, Andreas Wieser ${ }^{5}$, and Heini Wernli ${ }^{3}$ \\ ${ }^{1}$ Geophysical Institute, University of Bergen, Bergen, Norway \\ ${ }^{2}$ Bjerknes Centre for Climate Research, Bergen, Norway \\ ${ }^{3}$ Institute for Atmospheric and Climate Science, ETH Zürich, Zürich, Switzerland \\ ${ }^{4}$ Institute for Flight Guidance, Technical University Braunschweig, Braunschweig, Germany \\ ${ }^{5}$ Institute of Meteorology and Climate Research (IMK-TRO), Karlsruhe Institute of Technology (KIT), Karlsruhe, Germany \\ ${ }^{6}$ Picarro Inc., Santa Clara, California, USA \\ ${ }^{a}$ now at: Freeslate Inc., Sunnyvale, California, USA
}

Correspondence to: Harald Sodemann (harald.sodemann@uib.no)

Received: 12 August 2016 - Discussion started: 4 October 2016

Revised: 17 March 2017 - Accepted: 29 March 2017 - Published: 17 May 2017

\begin{abstract}
Stable isotopes of water vapour are powerful indicators of meteorological processes on a broad range of scales, reflecting evaporation, condensation, and air mass mixing processes. With the recent advent of fast laser-based spectroscopic methods, it has become possible to measure the stable isotopic composition of atmospheric water vapour in situ at a high temporal resolution. Here we present results from such comprehensive airborne spectroscopic isotope measurements in water vapour over the western Mediterranean at a high spatial and temporal resolution. Measurements have been acquired by a customized Picarro L2130-i cavity-ring down spectrometer deployed onboard the Dornier 128 DIBUF aircraft together with a meteorological flux measurement package during the HyMeX SOP1 (Hydrological cycle in Mediterranean Experiment special observation period 1) field campaign in Corsica, France, during September and October 2012. Taking into account memory effects of the air inlet pipe, the typical time resolution of the measurements was about $15-30 \mathrm{~s}$, resulting in an average horizontal resolution of about $1-2 \mathrm{~km}$. Cross-calibration of the water vapour measurements from all humidity sensors showed good agreement under most flight conditions but the most turbulent ones. In total 21 successful stable isotope flights with 59 flight hours have been performed. Our data provide quasi-climatological
\end{abstract}

autumn average conditions and vertical profiles of the stable isotope parameters $\delta \mathrm{D}, \delta^{18} \mathrm{O}$, and d-excess during the study period. A d-excess minimum in the overall average profile is reached in the region of the boundary-layer top, possibly caused by precipitation evaporation. This minimum is bracketed by higher d-excess values near the surface caused by non-equilibrium fractionation, and a maximum above the boundary layer related to the increasing d-excess in very depleted and dry high-altitude air masses. Repeated flights along the same pattern reveal pronounced day-to-day variability due to changes in the large-scale circulation. During a period marked by a strong inversion at the top of the marine boundary layer, vertical gradients in stable isotopes reached up to $25.4 \% \circ 100 \mathrm{~m}^{-1}$ for $\delta \mathrm{D}$ and $24.0 \% \circ 100 \mathrm{~m}^{-1}$ for the $\mathrm{d}$ excess.

\section{Introduction}

The vertical distribution of water vapour in the atmosphere is highly variable. It is shaped by source, transport, and sink processes, such as evaporation and condensation, horizontal and vertical advection, and mixing as determined by the atmospheric stability. The water vapour concentration itself 
does not provide information on the role different processes may play in its variability. The measurement of passive trace gases, such as carbon monoxide and methane, can provide insight into atmospheric mixing processes if significant sources are present at the surface but are not specific to water vapour. Considering the stable isotopic composition of atmospheric waters can support the interpretation of the phase change history of water vapour in an air mass. The isotopic composition in water vapour is here quantified by ratios between the concentration of the heavy stable isotopologues $\mathrm{H}_{2}^{18} \mathrm{O}$ and HDO and the most common isotopologue, $\mathrm{H}_{2}^{16} \mathrm{O}$, reported in $\delta$ notation as $\delta \mathrm{D}$ and $\delta^{18} \mathrm{O}$ in the water vapour (Coplen, 2011). It should be noted that the isotope ratios determined by laser spectroscopy are molecular isotope ratios. In practical cases it can be shown that the difference between the molecular ratios and the more commonly used atomic ratios derived from isotope-ratio mass spectrometry is much smaller than the measurement precision (Kerstel, 2004).

The temperature at which phase changes occur is the main driver of isotope fractionation that alters $\delta \mathrm{D}$ and $\delta^{18} \mathrm{O}$ due to the heavier isotopes preferring the more tightly bound phase. As more and more water vapour condenses and rains out from a cooling air mass, the remaining vapour thus becomes increasingly depleted of heavy isotopes, as described by the Rayleigh model (e.g. Gat, 2000). The isotopic composition of water vapour is also closely related to atmospheric transport as well as source (evaporation) and sink (condensation) processes (Jouzel et al., 1997) and can be seen as an integrating tracer of the water's Lagrangian transport history (Sodemann et al., 2008b). In the past, some of the most prominent uses of the stable isotope composition of water have been in a palaeoclimate context to infer past temperatures and moisture sources from natural archives (e.g. Jouzel et al., 1997), for ground water studies (e.g. Sonntag et al., 1983), and in studies investigating the stratospheric water budget (e.g. Webster and Heymsfield, 2003). The process-based insight provided by the isotope composition, however, also extends to synoptic and sub-diurnal timescales, and to the lower troposphere, where most atmospheric water vapour resides. In light of the key role of atmospheric moisture for the uncertainties in weather forecasts and climate predictions, understanding processes affecting isotopes on these timescales promises to serve as an additional constraint for future model improvements (e.g. Risi et al., 2012).

Historically, the isotopic composition of atmospheric water vapour has mainly been observed at the surface using cold traps or inferred indirectly from precipitation samples (e.g. Araguàs-Araguàs et al., 2000). Due to the difficult sampling procedures, the vertical distribution of stable isotopes in atmospheric water vapour has in the past been sampled only on very few occasions. Ehhalt and Östlund (1970) were the first to report $\delta \mathrm{D}$ from airborne samples made inside Hurricane Faith in 1966. Their measurements of water vapour and ice crystals collected in several vertical layers allowed develop- ing a hypothesis on the horizontal separation of updraft and downdraft shafts in tropical storms. Shortly thereafter, Taylor (1972) published a key data set of the isotopic composition in atmospheric water vapour from 20 flights made during 1967/68 over southern Germany. These profiles showed substantial vertical and temporal (daily to seasonal) variation. Atmospheric layers with remarkably different isotopic composition were interpreted as resulting from the combined influence of turbulent mixing within the boundary layer, as well as advection and subsidence above an inversioncapped boundary layer. Rozanski and Sonntag (1982) used a Rayleigh-type condensation model to interpret an average profile of Taylor's (1972) data. Their approach was disputed by Taylor (1984), noting that a model fit to averaged profiles will be meaningless unless the variability of each individual weather situation is taken into account. This controversy emphasized both the importance of the meteorological conditions during individual flights as well as the potential explanatory power of reliable climatological mean isotope profiles (Rozanski and Sonntag, 1984). Gedzelman (1988) devised a sophisticated multi-level adiabatic trajectory model to interpret the Taylor (1972) data by taking into account the pseudo-adiabatic ascent and dry adiabatic descent of the measured air masses. His study provided important insight into the control of cloud processing and vertical motion on the observed isotope profiles.

A second major stable isotope data set was obtained by Ehhalt (1974) (revised by Ehhalt et al., 2005) from repeated sampling flights during 1966-1967 and 1971-1973 over different parts of the US. The averaged profiles, obtained during different seasons and reaching up to $13 \mathrm{~km}$ altitude, revealed a general decrease in the heavy stable isotopes with height throughout the troposphere. Both season and location were significant for the variability of the mean profiles. Data points in and above the upper-troposphere-lowerstratosphere (UT/LS) region were less depleted than in the troposphere below, which was confirmed from balloon-based isotope sampling up to $20 \mathrm{~km}$ altitude (Pollock et al., 1980). Much of the further research was then focused on the UT/LS region, such as the collection of ice crystals in midlatitude storm tops (Smith, 1992), and airborne transects in the European Arctic at $400 \mathrm{hPa}$ to investigate the moisture budget of the stratosphere (Zahn et al., 1998). The isotope distribution in the atmospheric boundary layer and lower troposphere has received less attention from airborne measurement campaigns. He and Smith (1999) obtained vertical profiles from three flights in the boundary layer and the lower troposphere 20 years after the Taylor and Ehhalt flights. Albeit limited to a few data points, their results allowed deriving a first estimate of the stable isotope flux from the surface to the atmosphere. A similar analysis was done by Tsujimura et al. (2007) for a number of flights in the boundary layer and lower troposphere over Mongolia. 
All of the above flights suffered from the low temporal and spatial resolution available from a discrete sampling procedure. Samples were collected in cold traps, yielding only few samples per flight with a low temporal and spatial resolution. After the flight, stable isotope concentration was then determined in a laboratory from the collected water vapour with isotope-ratio mass spectrometry. Airborne in situ isotope measurements have only become possible with the advent of laser spectrometry. Since the first airborne deployment of a laser spectrometer by Webster and Heymsfield (2003) in the tropical UT/LS, a number of studies have investigated the isotopic composition in stratospheric water vapour and the tropical tropopause layer (Hanisco et al., 2007; Iannone et al., 2009; Sayres et al., 2009; Dyroff et al., 2010). In the context of validating remote-sensing products of the isotopic composition of water vapour, Dyroff's instrument has recently been deployed in the troposphere during seven flights in 2013 in the vicinity of the Canary Islands. The $\delta \mathrm{D}$ profiles acquired during these flights reveal very sharp vertical gradients related to air mass origin all the way through the troposphere (Dyroff et al., 2015). Similar features were apparent in $\delta \mathrm{D}$ measured during several airborne profiles up to $\sim 4500 \mathrm{~m}$ a.s.l. with a commercial laser spectrometer over interior Alaska (Herman et al., 2014). However, the isotopic composition in the lower troposphere and boundary layer themselves has so far not been interpreted with respect to the unprecedented information it can provide about the atmospheric transport history of water vapour.

The deuterium excess ( $\mathrm{d}$-excess $\left.=\delta \mathrm{D}-8 \cdot \delta^{18} \mathrm{O}\right)$, a secondorder isotope parameter, is a widely used measure of the degree of non-equilibrium conditions during stable isotope fractionation. The parameter quantifies the deviation of the isotopic composition from the empirical global meteoric water line (GMWL) which relates $\delta^{18} \mathrm{O}$ and $\delta \mathrm{D}$ in global precipitation to one another with a ratio of $1: 8$ (Dansgaard, 1964; Gat, 2000). During phase changes under non-equilibrium conditions, the different advection speeds of the HDO and $\mathrm{H}_{2}^{18} \mathrm{O}$ molecules lead to deviations from this empirical relationship. One example of this is evaporation into an unsaturated air mass, where strong winds prevent the system from reaching equilibrium. In such a case, there would be relatively more of the light and fast HDO molecules in the vapour phase than one would expect from the GMWL, hence the name deuterium excess. On a global average, the precipitation has a d-excess of about $10 \%$, indicating that evaporation and precipitation generally take place under non-equilibrium conditions. Under strong evaporation conditions characterized by atmospheres with low relative humidity, high dexcess of up to $40 \%$ has been observed in the vapour, in line with theoretical considerations (Merlivat and Jouzel, 1979; Pfahl and Sodemann, 2014), for example in the Mediterranean (Gat et al., 2003) or close to the sea-ice edge (Kurita, 2011). Note, however, that in highly depleted conditions with respect to $\mathrm{HDO}$ and $\mathrm{H}_{2}^{18} \mathrm{O}$, as encountered at higher tropospheric levels, the d-excess can take high values because of the non-linearity of the scale it is defined on (Uemura et al., 2012), even in the absence of kinetic fractionation (the dexcess becomes $7000 \%$ in the limiting case of $-1000 \%$ for both $\mathrm{HDO}$ and $\mathrm{H}_{2}^{18} \mathrm{O}$ ). Therefore, careful interpretation of this parameter is required.

Under the first-order approximation that these properties remain unaffected by the condensation history, the d-excess can serve as a tracer of moisture origin and source conditions (Merlivat and Jouzel, 1979; Aemisegger et al., 2014; Pfahl and Sodemann, 2014). Moisture over the Mediterranean Sea is known to have relatively high values of d-excess. During a cruise in January 1995, Gat et al. (2003) acquired samples with a d-excess ranging from 10 to $34 \%$, which they related to intense evaporation into dry continental air along the coast. Based on measurements of d-excess at Rehovot, Israel, Pfahl and Wernli (2008) modelled the range of dexcess over Mediterranean moisture sources as 15-40\%o for individual cases. Taylor (1972) concluded from his early airborne data that the d-excess would not provide any additional value. He and Smith (1999) reported both $\delta \mathrm{D}$ and $\delta^{18} \mathrm{O}$ but did not interpret the d-excess in their data. From airborne sampling of hydrometeors in Hurricane Olivia, Lawrence et al. (2002) found a pronounced day-to-day change in the d-excess, which was hypothesized to be due to evaporation condition changes. Current in situ instrumentation is in principle capable of providing d-excess measurements, yet this has not been exploited for interpreting the d-excess of lowertropospheric water vapour.

In this study, we report on airborne measurements of $\delta \mathrm{D}$, $\delta^{18} \mathrm{O}$, and the d-excess obtained from a custom-modified commercial cavity-ring down spectrometer (CRDS) with an enhanced laser setup. Measurements were performed during a 30-day period in the boundary layer and the lower troposphere around Corsica, France, in the western Mediterranean, yielding 21 successful flights with about 59 flight hours. The aircraft was based at Solenzara, Corsica, during the first HyMeX (Hydrological cycle in the Mediterranean experiment, Drobinski et al., 2014) special observations period (SOP1) in September-October 2012, providing many additional observations from different platforms in the region (Ducrocq et al., 2014).

After describing the measurement campaign, data acquisition system, and data processing (Sect. 2), we present and interpret a quasi-climatological autumn vertical isotope profile of water vapour over the western Mediterranean from all available isotope flight data (Sects. 3 and 4). Then, we examine the temporal evolution of the isotope profiles on several days along a repeated flight track, exemplifying the tight coupling of the isotopic composition to synoptic processes (Sect. 5). For a single flight, detailed back-trajectory analysis shows that the isotopic composition, including d-excess, provides additional insight into moisture origin and evaporation processes (Sects. 6 and 7). Finally, we provide a summary and conclude with the main results of the study (Sect. 8). 
Table 1. Instrumentation onboard the Do 128-6 during HyMeX SOP1.

\begin{tabular}{lllr}
\hline Parameter & Measurement principle & Type and manufacturer & Measurement frequency \\
\hline Specific humidity & Dew point mirror & TP3, Meteolabor & Variable \\
& Lyman- $\alpha$ & Buck Research & $100 \mathrm{~Hz}$ \\
& Humicap hygrometer & HMP 233, Humicap & $100 \mathrm{~Hz}$ \\
& CRDS laser spectrometer & L2130-i, Picarro Inc. & $1 \mathrm{~Hz}$ \\
$\delta \mathrm{D}, \delta^{18} \mathrm{O}$ & CRDS laser spectrometer & L2130-i, Picarro Inc. & $1 \mathrm{~Hz}$ \\
Temperature & PT100 open wire & Rosemount & $100 \mathrm{~Hz}$ \\
Pressure & Five-hole probe and pressure transducers & Rosemount & $100 \mathrm{~Hz}$ \\
Surface temperature & Infrared radiometer & Heiman KT15 & $1 \mathrm{~Hz}$ \\
Wind speed & Calculated from flight parameters & & $100 \mathrm{~Hz}$ \\
\hline
\end{tabular}

\section{Data}

\subsection{Airborne measurements during the HyMeX campaign}

In autumn 2012 (5 September-6 November 2012), HyMeX SOP1 took place in the western Mediterranean. In addition to the implementation of extensive ground-based field measurements on Corsica (Kalthoff et al., 2013; Barthlott et al., 2014), airborne measurements were carried out in the vicinity and above the island from 11 September to 11 October 2012, using the Dornier 128-6 (D-IBUF) research aircraft of the Institute of Flight Guidance, TU Braunschweig (Corsmeier et al., 2001). The dual-engine propeller aircraft has a typical cruising speed of $65 \mathrm{~m} \mathrm{~s}^{-1}$ and can reach altitudes of up to $24500 \mathrm{ft}$ ( $\sim 7300 \mathrm{~m}$ ) with oxygen masks in the non-pressurized cabin, even though flight altitude did not exceed $4500 \mathrm{~m}$ during this campaign. The aircraft instrumentation provided a unique setup to simultaneously gather information on evaporation fluxes and the corresponding isotopic composition in the marine boundary layer. Onboard instrumentation consisted of a comprehensive package for airborne meteorological flux measurements in the nose boom acquiring humidity, wind vectors, temperature, and pressure at a $100 \mathrm{~Hz}$ sampling rate - and short-wave and long-wave radiation sensors for the upper and lower half-space and radiative surface temperature as well as additional humidity sensors with lower sampling frequency (Table 1). The isotopic composition of ambient water vapour was measured using a commercial CRDS instrument (L2130-i, Picarro Inc.). The instrument was customized, resulting in a data acquisition rate of up to $2 \mathrm{~Hz}$ by a triple-laser setup allowing faster measurement of the different wavelengths for HDO and $\mathrm{H}_{2}^{18} \mathrm{O}$ molecules. During the HyMeX campaign, the instrument was used in a scheme with two ring-downs per data point, resulting in a $1 \mathrm{~Hz}$ data acquisition rate. Outside air was guided into the system through a backward-facing cabinmounted stainless-steel inlet connected to a bypass pump (see Appendix A1). No additional trace gas measurements were available during the aircraft campaign.

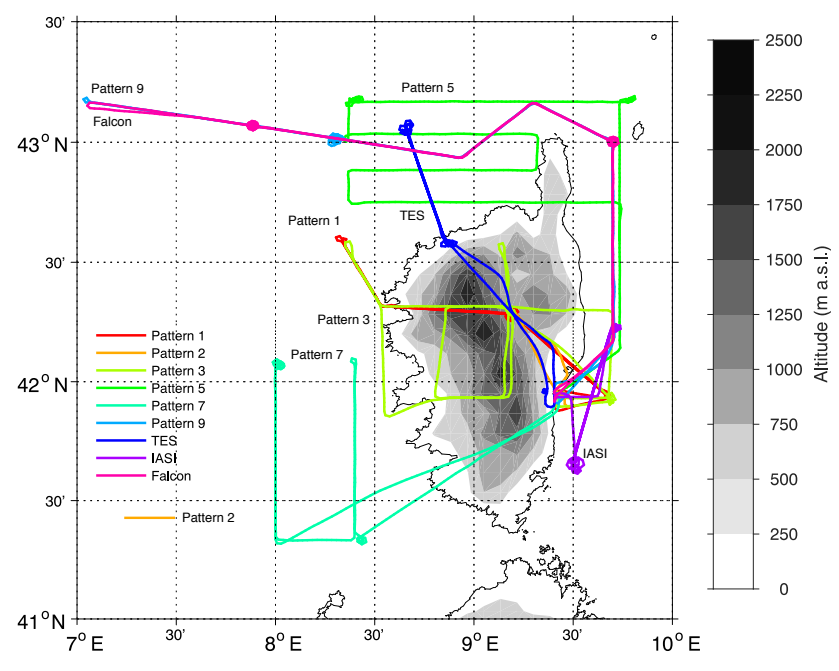

Figure 1. Flight patterns during the HyMeX IBUF campaign. Grey shading shows elevation in metres above sea level ( $\mathrm{m}$ a.s.1.). Table 1 lists the dates when the different patterns were flown.

In total 32 flights were performed (Table 2). During 11 flights (flights 17-27) the bypass pump was not working, thus a mixture of cabin and outside air was sampled by the laser spectrometer in those cases. Here, only the 21 flights are reported during which all pumps were working. Figure 1 summarizes the flight patterns for these 21 flights. The different flight patterns were primarily designed to provide information of the thermodynamic environment above and around Corsica leading to moist convection, including surface evaporation and boundary-layer processes over the island and the surrounding ocean. Thereby, flight patterns did both provide statistically robust sampling of the atmosphere at levels of constant altitude in the boundary layer and free troposphere, and profiles of the vertical structure of the atmosphere above land and water. Flight operations were focused on altitudes below $2000 \mathrm{~m}$ a.s.l. but reached above $4500 \mathrm{~m}$ a.s.l. for a few vertical profiles. The flight patterns were often repeated after several hours or on the next day to investigate the changes in the atmosphere with the diurnal cycle or during a specific weather situation (Table 2). 


\subsection{Correction and calibration of humidity measurements}

Reliable measurements of humidity are an important basis for the interpretation of the isotope data. Four independent humidity measurements were available on the aircraft: a dew point mirror hygrometer (TP), a Humicap capacitive sensor hygrometer (HC), a Lyman- $\alpha$ hygrometer (LY), and the CRDS $\mathrm{H}_{2}^{16} \mathrm{O}$ concentration (Table 1). The Lyman$\alpha$ measures at a very high frequency $(100 \mathrm{~Hz})$ but needs to be combined with slower accurate measurements from either the Humicap or the dew point mirror for bias correction. The combination of the Lyman- $\alpha$ with the dew point mirror (TPLY) provides a fast response to changing ambient conditions and generally stable measurements, even if sometimes after encountering very dry conditions it delivered bad data. In this study, the combined Lyman- $\alpha$-Humicap humidity product (HCLY) was used as a reference for calibrating the CRDS humidity measurements because it had a response time similar to the CRDS measurements. The correspondence between the CRDS and the HCLY humidity allowed compensating for time shifts of the stable isotope measurements due to the inlet, piping, position in the aircraft, and computer clock differences. Humidity measurements from the CRDS were then calibrated with the HCLY humidity data using a linear fit determined from each individual flight at a $1 \mathrm{~Hz}$ time resolution. The slope and offset of this linear fit were mostly stable between flights but changed after the installation of a replacement pump after the first bypass pump failed (see Appendix A2). The Humicap was calibrated repeatedly during the campaign and showed very stable calibration curves.

An example of the uncalibrated $1 \mathrm{~Hz}$ humidity data from flight 01 is shown in Fig. 2a. Flights with strong turbulence showed slightly lower correlations. From the generally high correlation between the two humidity measurements at $1 \mathrm{~Hz}$, it is apparent that for $\mathrm{H}_{2}^{16} \mathrm{O}$ only very limited memory effects were introduced by the inlet system. During many flight periods the CRDS humidity measurement was more similar to the HCLY than to the humidity derived from the dew-point mirror-Lyman- $\alpha$ combination, as exemplified in Fig. 2b. Both aspects support the fact that the CRDS instrument provided reliable measurements during most flight conditions and was generally able to compensate for ambient pressure and temperature changes during the flight (see Appendix A5).

\subsection{Water vapour dependency correction of the stable isotope measurements}

The CRDS measurements of the isotopic composition of water vapour are affected by a mixing-ratio-dependent bias and therefore require a water vapour dependency correction, sometimes also referred to as a humidity-isotope response calibration, prior to or during the calibration of the
Table 2. Flight dates and corresponding pattern during the HyMeX D-IBUF deployment. During flights $17-26$ printed in italic the bypass pump of the stable isotope measurements was not working. TES: Tropospheric Emission Spectrometer; IASI: Infrared Atmospheric Sounding Interferometer.

\begin{tabular}{|c|c|c|c|c|c|}
\hline $\begin{array}{l}\text { Flight } \\
\text { number }\end{array}$ & Date & $\begin{array}{l}\text { Takeoff } \\
\text { (UTC) }\end{array}$ & $\begin{array}{l}\text { Landing } \\
\text { (UTC) }\end{array}$ & $\begin{array}{l}\text { Duration } \\
\text { (h) }\end{array}$ & Pattern \\
\hline 01 & 11 Sept 2012 & 11:01 & $14: 00$ & $2: 59$ & 1 \\
\hline 02 & 12 Sept 2012 & $07: 59$ & 11:05 & 3:06 & 5 \\
\hline 03 & 12 Sept 2012 & $14: 07$ & $17: 19$ & $3: 12$ & 5 \\
\hline 04 & 13 Sept 2012 & $07: 56$ & $10: 45$ & $2: 49$ & 5 \\
\hline 05 & 13 Sept 2012 & 13:07 & $13: 47$ & $0: 40$ & 2 \\
\hline 06 & 14 Sept 2012 & 08:00 & 11:06 & 3:06 & 5 \\
\hline 07 & 17 Sept 2012 & $10: 54$ & $12: 41$ & $1: 47$ & 1 \\
\hline 08 & 18 Sept 2012 & 08:59 & $12: 01$ & 3:02 & 1 \\
\hline 09 & 20 Sept 2012 & $07: 53$ & $10: 53$ & 3:00 & 3 \\
\hline 10 & 21 Sept 2012 & $06: 56$ & $09: 58$ & 3:02 & 3 \\
\hline 11 & 21 Sept 2012 & $11: 23$ & $14: 26$ & $3: 03$ & 3 \\
\hline 12 & 23 Sept 2012 & $06: 55$ & 10:03 & 3:08 & 1 \\
\hline 13 & 23 Sept 2012 & 11:00 & $14: 07$ & 3:07 & 1 \\
\hline 14 & 24 Sept 2012 & $11: 56$ & $15: 14$ & $3: 18$ & 9 \\
\hline 15 & 25 Sept 2012 & 07:01 & 10:09 & 3:08 & 1 \\
\hline 16 & 25 Sept 2012 & 11:09 & $14: 11$ & $3: 02$ & 1 \\
\hline 17 & 27 Sept 2012 & $12: 54$ & $16: 20$ & $3: 26$ & 9 \\
\hline 18 & 28 Sept 2012 & $10: 00$ & $13: 18$ & $3: 18$ & TES \\
\hline 19 & 28 Sept 2012 & $14: 05$ & $15: 35$ & $1: 30$ & 1 \\
\hline 20 & 1 Oct 2012 & $08: 55$ & $11: 30$ & $2: 35$ & 2 \\
\hline 21 & 1 Oct 2012 & 13:04 & 16:07 & $3: 03$ & 2 \\
\hline 22 & 2 Oct 2012 & $08: 58$ & $12: 09$ & $3: 11$ & 1 \\
\hline 23 & 2 Oct 2012 & $13: 39$ & $16: 32$ & $2: 53$ & 1 \\
\hline 24 & 3 Oct 2012 & $08: 50$ & $12: 01$ & $3: 11$ & 3 \\
\hline 25 & 3 Oct 2012 & 13:09 & $16: 33$ & $3: 24$ & 3 \\
\hline 26 & 4 Oct 2012 & $08: 42$ & $12: 10$ & $3: 28$ & 5 \\
\hline 27 & 4 Oct 2012 & $12: 59$ & $15: 53$ & $2: 54$ & 7 \\
\hline 28 & 5 Oct 2012 & $07: 31$ & $10: 36$ & 3:05 & IASI \\
\hline 29 & 5 Oct 2012 & 13:09 & $14: 38$ & $1: 29$ & 3 \\
\hline 30 & 9 Oct 2012 & $08: 57$ & $11: 37$ & $2: 40$ & 1 \\
\hline 31 & 10 Oct 2012 & $11: 35$ & $13: 55$ & $2: 20$ & 3 \\
\hline 32 & 11 Oct 2012 & $06: 36$ & $10: 03$ & $3: 27$ & Falcon \\
\hline
\end{tabular}

isotopes themselves (Sturm and Knohl, 2010; Aemisegger et al., 2012; Bastrikov et al., 2014; Bailey et al., 2015). A first humidity-isotope response calibration was performed in the laboratory in October 2012 (immediately after the field deployment) using a WVISS (water vapour isotopic standard source) unit (Los Gatos Inc.) for standard vapour generation and a stable isotope working standard also used for the calibration of the measurements (Sect. 2.4). In autumn 2014 this was extended to lower humidities with the same CRDS and an improved setup using a dew point generator (Li-610, Licor Inc.). We measured the humidity-isotope response during stepwise increases in water concentration from 500 to $10000 \mathrm{ppmv}$ and fitted a power law function forced to 0 at and above the reference level of $10000 \mathrm{ppmv}$ for each 

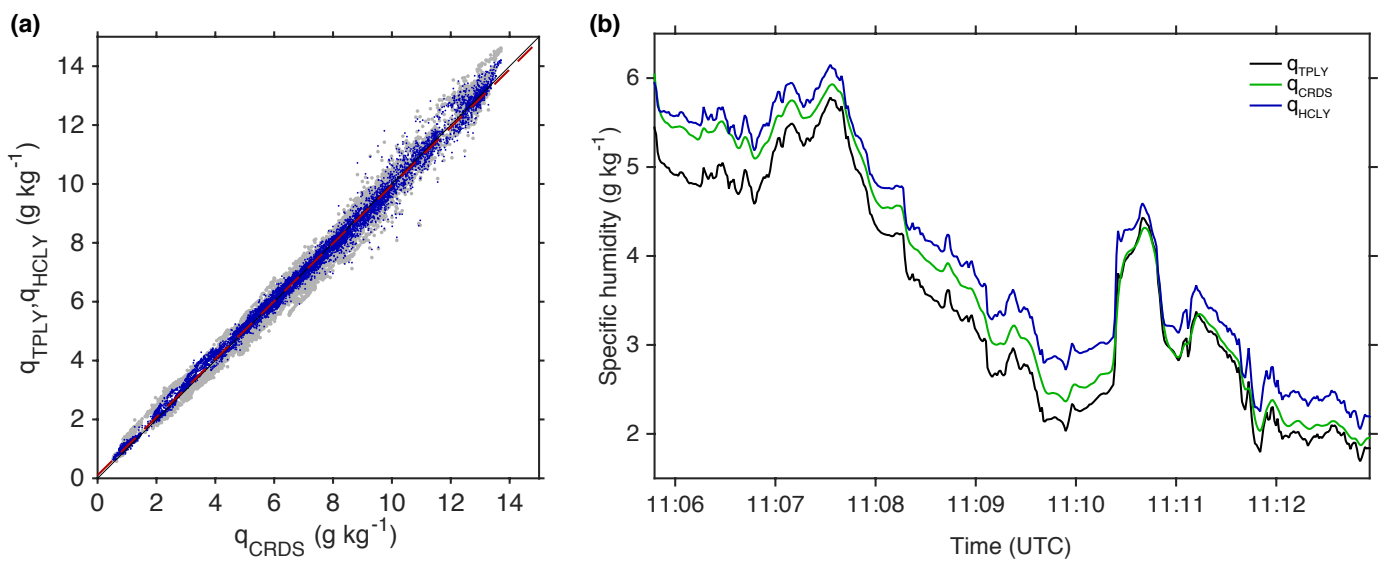

Figure 2. (a) Correlation between calibrated specific humidity from the CRDS $\left(q_{\mathrm{CRDS}}\right)$, the Humicap-Lyman- $\alpha$ ( $q_{\mathrm{HCLY}}$, blue dots, $\rho=$ $0.994)$, and the dew point hygrometer-Lyman- $\alpha$ product ( $q$ TPLY; grey dots; $\rho=0.989$ ) at $1 \mathrm{~s}$ time interval for flight 01 on 11 September 2012. Red dashed line shows a linear least-squares fit to the $q_{\mathrm{HCLY}}$ and $q_{\mathrm{CRDS}}$ data; black line is a $1: 1$ relation. (b) Comparison of calibrated humidity measurements from the three products for a representative vertical profile during flight 01 ascending from $1500 \mathrm{~m}$ to $3700 \mathrm{~m}$ a.s.l.

isotopologue:

$\Delta \delta^{18} \mathrm{O}=a\left(w_{\text {raw }}^{b}-10000^{b}\right)$,

$\Delta \delta \mathrm{D}=c\left(w_{\text {raw }}^{d}-10000^{d}\right)$,

where $w_{\text {raw }}$ is the uncalibrated volume mixing ratio of water vapour from the CRDS in units of parts per million by volume, and the coefficients are $a=1.0856 \times 10^{4}, b=-1.1068$, $c=2.0578 \times 10^{4}$, and $d=-1.0774$. The calibration functions increase strongly for mixing ratios below $3000 \mathrm{ppmv}$ (up to $2.7 \%$ or $\delta \mathrm{D}, 1.9 \%$ or for $\delta^{18} \mathrm{O}$ ). For d-excess, the correction reaches $-12.8 \%$ at 3000 ppmv (Appendix A3), underlining the particular importance of humidity-isotope response calibration for this parameter. In the current generation of the L2130-i Picarro instrument, the response is less pronounced than in earlier instrument generations (Aemisegger et al., 2012), but it is different for each individual instrument (compare, e.g., Bastrikov et al., 2014). We consider the humidity dependency of the stable isotope measurements as an instrument characteristic that remained constant during the campaign, as confirmed by repeated measurements during and after the campaign in 2012 (Appendix A3).

\subsection{Stable isotope measurements calibration}

The calibration of the CRDS instrument was routinely performed with the WVISS calibration unit using two working standards WS6 and WS9 (WS6; $\delta \mathrm{D}:-78.7 \pm 0.2 \%$; $\delta^{18} \mathrm{O}:-11.0 \pm 0.1 \%$; WS9; $\delta \mathrm{D}:-166.7 \pm 0.4 \%$; $\delta^{18} \mathrm{O}$ : $-70.2 \pm 2.7 \%$ o, determined from isotope-ratio mass spectrometry; Aemisegger, 2013), which approximately span the range of the field measurements (albeit lower $\delta \mathrm{D}$ conditions were encountered). On every day with flight activity at least six calibration runs were performed with a duration of $10 \mathrm{~min}$ each. Before the flight, one calibration run at a water vapour mixing ratio of $\sim 20000$ ppmv was done with both standards. After the flight two runs per standard at water vapour mixing ratios of $\sim 4000$ and $\sim 20000 \mathrm{ppmv}$ were performed. Ambient air dried with the WVISS unit was used as carrier gas for the calibrations. Most of the calibration runs before the flights had to be discarded because it was later established that the laser spectrometer and the WVISS had not yet sufficiently stabilized after start-up. Thus, with very few exceptions only the calibration runs carried out after the daily flight operations were used for the calibration of the isotope measurements, using the constant part of each 10 min calibration period for averaging. As empirical stability criteria, the $1 \sigma$ standard deviation during this period had to be below $3 \%$ o for $\delta \mathrm{D}\left(2 \%\right.$ for $\left.\delta^{18} \mathrm{O}\right)$ for taking an individual calibration run into consideration. Calibrations were then done following the procedure recommended by IAEA (2009).

No isotope calibrations were performed during the flight due to lack of an onboard calibration system. In principle, instability can occur due to temperature and pressure fluctuations in the measurement cavity. Cavity pressure and temperatures inside the instrument are continuously stabilized, and records of these parameters indicate that no adjustment problems were encountered during most flight conditions (Appendix A5). Furthermore, the humidity measurement of the L2130-i is based on the spectral absorption of the $\mathrm{H}_{2} \mathrm{O}$ molecule and uses the same measurement principle as for the other isotopologues. Therefore, if the stable isotope measurements were affected by strong drifts during the flights we expect that this would also be detectable in the humidity measurements. This was not observed; the high correlation between the HCLY and CRDS humidity (Fig. 2) is therefore also considered to be a first-order indication for the stability of the isotope measurements during the flight. At least for our study with a relatively short flight time, regular calibration during the flight would not necessarily improve the data 
quality but substantially reduce the available measurement time. It therefore seems that precise temperature and pressure regulation of the cavity and the other instrument parts is the most important requirement to limit the uncertainty of our airborne stable isotope data.

\subsection{Data quality and resolution}

Memory effects due to interaction with the piping walls are larger and species dependent for $\mathrm{H}_{2}^{18} \mathrm{O}$ and HDO compared to $\mathrm{H}_{2}^{16} \mathrm{O}$. The influence of these effects on the inlet system were tested in a laboratory setup after the field campaign. To this end, the inlet system from the aircraft (Fig. A1) was reassembled in the laboratory and extended by a set of switching valves that allowed the application of an airstream at either $\sim 3000$ ppmv or $\sim 10000$ ppmv humidity from two different calibration units to the stainless steel end of the inlet system. These switching experiments yielded a time constant of $2.3 \mathrm{~s}$ for $\delta \mathrm{D}\left(1.7 \mathrm{~s}\right.$ for $\left.\delta^{18} \mathrm{O}\right)$ for switches from lower to higher isotope concentrations and vice versa (Aemisegger, 2013). This causes smoothing over $\sim 2-3$ data points at a $1 \mathrm{~Hz}$ time resolution at standard pressure and moderate humidity ranges. At lower humidity levels and lower air pressure, it is likely that these time constants increase and also lead to an increased memory effect during vertical (upward) profiles from moist into dry air layers (see below).

Stability tests of the CRDS isotope measurements were performed before, during and after the HyMeX campaign using the WVISS as a standard vapour source (Aemisegger, 2013). For these tests, calibration standard WS6 was measured for several hours at a water vapour mixing ratio of $\sim 9000$ ppmv. Stability was assessed using the Allan deviation. The stability of the measurements degraded during the campaign, possibly because of modifications to the mounting of the optical fibers inside the CRDS, which had to be done for the flight certification of the instrument. These issues also affected instrument stabilization and increased warmup time (up to $2 \mathrm{~h}$ ). While any resulting drifts were removed by calibration, precision generally decreased. At the averaging times considered here, this mainly affected the d-excess during the later flights of the campaign.

From long-term stability tests, the standard deviation of the measurements during the campaign for an averaging time of $60 \mathrm{~s}$ was $2.3 \%$ for $\delta \mathrm{D}, 0.36 \%$ for $\delta^{18} \mathrm{O}$, and $1.18 \%$ 。 for d-excess (Table 3). The dependency between averaging times, horizontal and vertical resolution, and standard deviation for all isotopic parameters is summarized in Table 3. The $1 \sigma$ standard deviation increased considerably at lower water concentrations (Appendix A4). Generally, the practical meaning of the standard deviations is somewhat limited, as the atmospheric isotope composition exhibited substantial variability on timescales of seconds to minutes, in particular in the free troposphere (see below). As changing evaporation conditions are expected to create signals in the d-excess on the order of $10 \%$ and more, significant differences are
Table 3. Relation between averaging times and standard deviations, and the resulting vertical and horizontal resolution at typical true air speed of $65 \mathrm{~m} \mathrm{~s}^{-1}$ horizontally and $5 \mathrm{~ms}^{-1}$ vertically at a volume mixing ratio of $9000 \mathrm{ppmv}$.

\begin{tabular}{lrrrrrr}
\hline $\begin{array}{l}\text { Averaging } \\
\text { time (s) }\end{array}$ & 5 & 10 & 15 & 30 & 60 & 180 \\
\hline$\delta \mathrm{D}(\% \circ)$ & 2.47 & 2.39 & 2.36 & 2.33 & 2.32 & 2.33 \\
$\delta^{18} \mathrm{O}(\% \circ)$ & 0.50 & 0.43 & 0.40 & 0.38 & 0.36 & 0.35 \\
$\begin{array}{l}\text { D-excess (\%o) } \\
\text { Horizontal }\end{array}$ & 3.17 & 2.29 & 1.91 & 1.47 & 1.18 & 0.93 \\
$\begin{array}{l}\text { resolution (m) } \\
\begin{array}{l}\text { Vertical } \\
\text { resolution (m) }\end{array}\end{array}$ & 25 & 650 & 975 & 1950 & 3900 & 11700 \\
\hline
\end{tabular}

detectable at a 30-60 s averaging time, providing a d-excess with a spatial resolution of up to $2-4 \mathrm{~km}$ horizontally and $150-300 \mathrm{~m}$ vertically when descending at $5 \mathrm{~m} \mathrm{~s}^{-1}$ (Table 3 ). For the analysis presented here, we report $15 \mathrm{~s}$ averages for $\delta \mathrm{D}$ and $\delta^{18} \mathrm{O}$ and $30 \mathrm{~s}$ averages for the d-excess unless stated otherwise. Since the d-excess measures how $\delta^{18} \mathrm{O}$ deviates from the behaviour expected at equilibrium conditions, we do not report the $\delta^{18} \mathrm{O}$ in detail here. Thus, we focus the discussion of our own measurements mostly on the complementary parameters $\delta \mathrm{D}$ and d-excess.

\subsection{Meteorological background conditions}

The climate of Corsica in autumn is characterized by warm sea waters and the progressively increasing influence of cold air masses from northern directions. Climatological rainfall totals in Bastia $\left(42^{\circ} 33^{\prime} \mathrm{N}, 9^{\circ} 29^{\prime} \mathrm{E}\right)$ increase from $65 \mathrm{~mm}$ in September to $110 \mathrm{~mm}$ in October (the wettest month of the year), albeit with large inter-annual variability. Isolated deep convection frequently develops over the mountainous island in autumn, favoured by an inland transport of water vapour via thermally driven circulations (Barthlott et al., 2014; Adler et al., 2015). On the east coast north of Solenzara, $2 \mathrm{~m}$ air temperatures measured at the energy balance station San Giuliano ranged between about 20 and $27^{\circ} \mathrm{C}$ during the day and $15-20^{\circ} \mathrm{C}$ at night during the campaign period, with a rainfall total of $222 \mathrm{~mm}$ for the 2-month period from $25 \mathrm{Au}$ gust 2016 to 25 October 2016.

The climatological isotopic composition of atmospheric moisture and sea water in this region is not known. Nonrepresentative river runoff samples taken at two elevations in the eastern part of the island during the campaign suggest weakly depleted precipitation and enhanced non-equilibrium fractionation at the moisture source prior to atmospheric transport $(-41.7 \pm 0.8 \%$ in $\delta \mathrm{D}$ and $13.9 \pm 1.6 \%$ in d-excess at $1000 \mathrm{~m}$ a.s.l.). The signal was similar but slightly weaker further downstream, possibly due to evaporation of ground water and river runoff $(-39.5 \pm 0.8 \%$ in $\delta \mathrm{D}$ and $9.7 \pm 1.6 \%$ o in d-excess at $15 \mathrm{~m}$ a.s.1.). Coastal sea water from Solenzara in contrast was enriched, and showed indications of non- 
equilibrium fractionation due to ocean evaporation $(9.3 \pm$ $0.8 \%$ in $\delta \mathrm{D}$ and $-4.0 \pm 1.8 \%$ in d-excess from two samples). Due to the small sample size, these values only provide approximate differences.

Vertical profiles of average humidity, temperature, and wind speed from all flights with valid isotope measurements (Table 2) are shown in Fig. 3. Humidity decreases fairly linearly with height, and has largest variations at low levels, ranging between 5 and $17 \mathrm{~g} \mathrm{~kg}^{-1}$ (Fig. 3a). Above $1500 \mathrm{~m}$ a.s.l., very low-humidity conditions were encountered, while variability remained substantial up to the highest flight altitudes. Temperatures ranged between 18 and $32^{\circ} \mathrm{C}$ at the ground and decreased with an average lapse rate of $5.1 \mathrm{~K} \mathrm{~km}^{-1}$ (Fig. 3b). Between elevations of 1500 and $3000 \mathrm{~m}$ a.s.l., some excursions to colder than average conditions can be noted, which were associated with the advection of cold air from northerly directions during flights 04 and 05 (not shown). Horizontal wind speeds were generally weak during the flights, mostly below $10 \mathrm{~m} \mathrm{~s}^{-1}$ near the ground, with some excursions of above $20 \mathrm{~m} \mathrm{~s}^{-1}$ (Fig. 3c). Average wind was increased above $2000 \mathrm{~m}$ a.s.l. in the free troposphere, but remained at a moderate $10-15 \mathrm{~m} \mathrm{~s}^{-1}$. Thus, the typical advection speed was below $400 \mathrm{~km} \mathrm{day}^{-1}$ in the boundary layer and on the order of $800-1200 \mathrm{~km} \mathrm{day}^{-1}$ in the free troposphere.

The aircraft operated outside of clouds (visible flight rules, VFRs) throughout the campaign. Therefore, relative humidity with respect to liquid (RH) remained below saturation at the aircraft location for $<99 \%$ of all data points (not shown). Average cloudiness during the campaign was also low, as subsidence dominated on the large scale. The exception were several days with strong thunderstorms at the beginning of the campaign period (2-5 September 2012).

\section{Mean vertical stable isotope profiles}

Figure 4 displays the averaged isotopic composition in the western Mediterranean from all corrected and calibrated data from the 21 flights. The measurements reveal an unprecedented level of detail of the isotope distribution in the western Mediterranean lower troposphere. The $200 \mathrm{~m}$ binned vertical profiles of the main isotopes $\delta \mathrm{D}$ and $\delta^{18} \mathrm{O}$ have distinct, coherent shapes, showing an overall decrease from close to the surface $(\delta \mathrm{D}=-96.7 \%$ o and $\delta^{18} \mathrm{O}=-14.1 \%$ o between 0 and $200 \mathrm{~m}$ a.s.l.) to the free troposphere $\left(\delta \mathrm{D}=-225.1 \% \circ\right.$ and $\delta^{18} \mathrm{O}=-30.2 \%$ between 3400 and $3600 \mathrm{~m}$ a.s.l.; Fig. $4 \mathrm{a}$ and $\mathrm{b}$, thick red lines). The vertical gradients were $-36.7 \% \mathrm{~km}^{-1}$ for $\delta \mathrm{D}$ and $-4.2 \% \mathrm{~km}^{-1}$ for $\delta^{18} \mathrm{O}$. At all elevations, the distribution is skewed towards the minimum values, as is apparent from the horizontal stripes of data points acquired during longer horizontal transects. For this reason, the bin minimum and maximum values are discussed, rather than the standard deviation. The bin maximum values decrease less strongly than the bin means with vertical gradients of $-16.7 \% \mathrm{~km}^{-1}$ for $\delta \mathrm{D}$ and $-2.1 \% \mathrm{~km}^{-1}$ for $\delta^{18} \mathrm{O}$ (Fig. 4a and b, red dashed lines). The bin minimum values show a distinct decrease between 1700 and $2300 \mathrm{~m}$ a.s.1., which is to some extent reflected in the mean and also leads to stronger vertical gradients of the minimum values $\left(-51.9 \% \mathrm{~km}^{-1}\right.$ for $\delta \mathrm{D},-6.0 \% \mathrm{~km}^{-1}$ for $\delta^{18} \mathrm{O}$ ). While there are indications for further decreasing mean values above $3700 \mathrm{~m}$ a.s.l., data are only available from one flight and are thus not sufficient to extend the bin averaging to these elevations.

The shape of the composite vertical profile of the d-excess is different from that of the primary stable isotope parameters (Fig. 4c). Mean values show a maximum close to the surface $(16.0 \%$ o between 0 and $200 \mathrm{~m}$ a.s.1.), decrease to an overall minimum bin mean of $4.9 \%$ o between 1200 and $1400 \mathrm{~m}$ a.s.l., and then increase again to bin mean values of $8-9 \%$ above $2800 \mathrm{~m}$ a.s.l. The bin minimum values are negative throughout the profile (overall minimum $-15.7 \%$ at $1300 \mathrm{~m}$ a.s.1.). The d-excess maximum values show a marked linear decrease from $60.2 \%$ close to the surface (between 0 and $200 \mathrm{~m}$ a.s.1.) to about $21.2 \%$ at $1500 \mathrm{~m}$ a.s.l. and again a marked increase above $1700 \mathrm{~m}$ a.s.l. to relatively uniform maximum values around $60 \%$ above 2000 m a.s.l. Many of the high d-excess values aloft have been sampled during relatively dry conditions $\left(q<2 \mathrm{~g} \mathrm{~kg}^{-1}\right.$, indicated by the blue dots). The overall minimum in d-excess at $1300 \mathrm{~m}$ a.s.l. is an interesting finding, which is further investigated in Sect. 4.2.

It is known from several other studies that uppertropospheric water vapour can have high d-excess values (Galewsky et al., 2011; Samuels-Crow et al., 2014). They are partly due to the definition of the d-excess as a function of $\delta \mathrm{D}$ and $\delta^{18} \mathrm{O}$ with a constant slope and to the nonlinearity of the delta scale. This provides further evidence that the high d-excess encountered above the marine boundary layer is not an indication of insufficient data quality but a real feature of the isotopic composition in the atmosphere. That said, the precision of the d-excess measurements from the CRDS instrument (in terms of signal-to-noise ratio) decreased substantially at very low humidity during the flight (see Appendix A4). This is also where the humidity dependency response is most influential (see Appendix A2).

\subsection{Comparison to previous airborne isotope measurements}

We now compare our western Mediterranean measurements to previous airborne isotope measurements in other regions. A comprehensive sampling of stable isotopes in tropospheric water vapour was carried out by Ehhalt (1974) during 196567 and 1971-1973 over three marine and continental sites in the US. These $\delta \mathrm{D}$ data are from water vapour collected in cold traps during flight legs at constant altitude for 10$60 \mathrm{~min}$. The data cover a large variety of weather conditions from all seasons and different climatic regimes (Fig. 5a). There is a clear correspondence between the envelope of the 

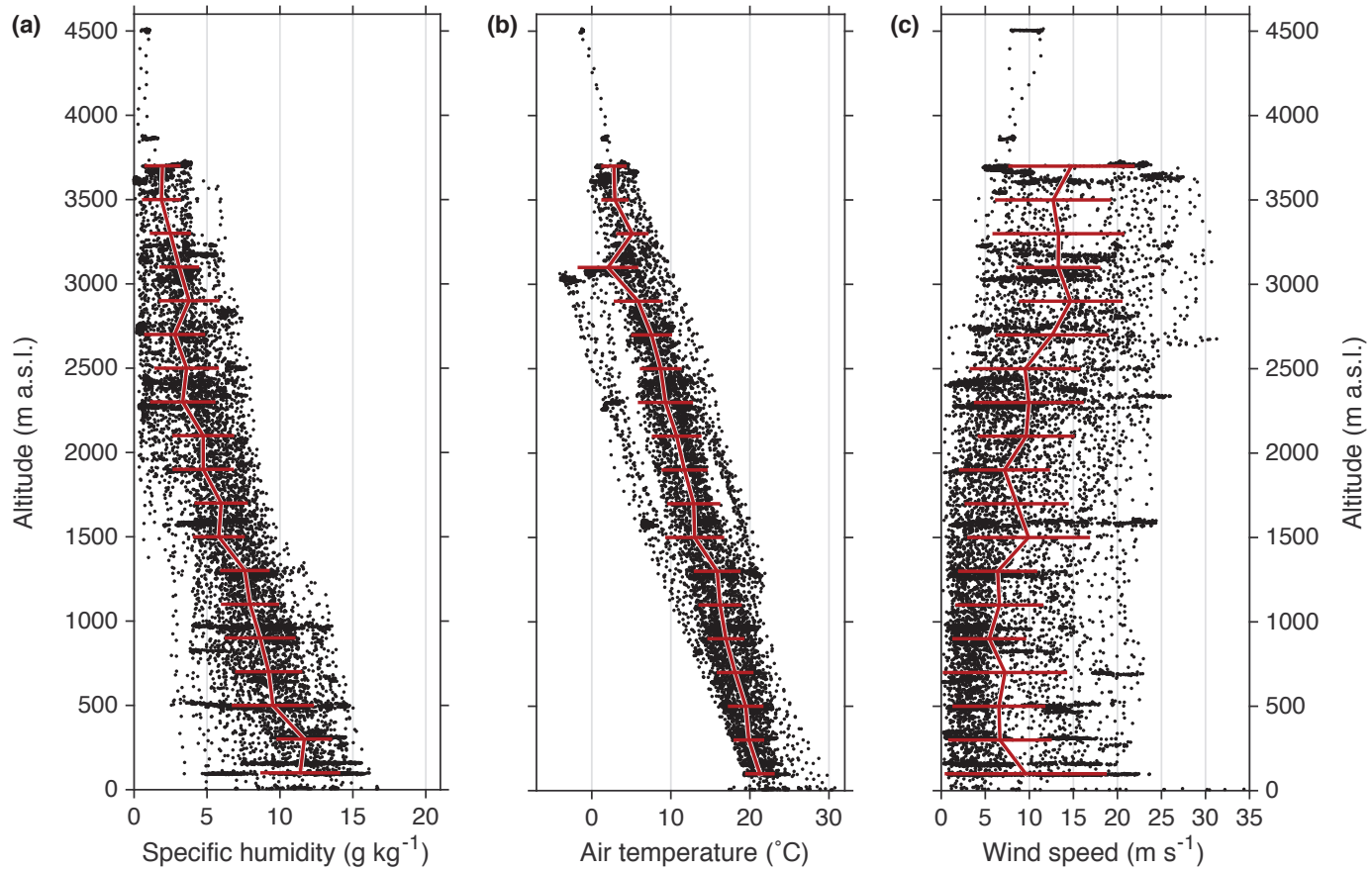

Figure 3. Vertical profiles of the mean thermodynamic and kinematic state of the atmosphere observed during the campaign. (a) Specific humidity from HCLY in gram per kilogram; (b) air temperature in kelvin; (c) horizontal wind speed in metres per second. Overlaid are the $200 \mathrm{~m}$ binned averages as red lines. Horizontal red bars denote the bin $1 \sigma$ standard deviation.
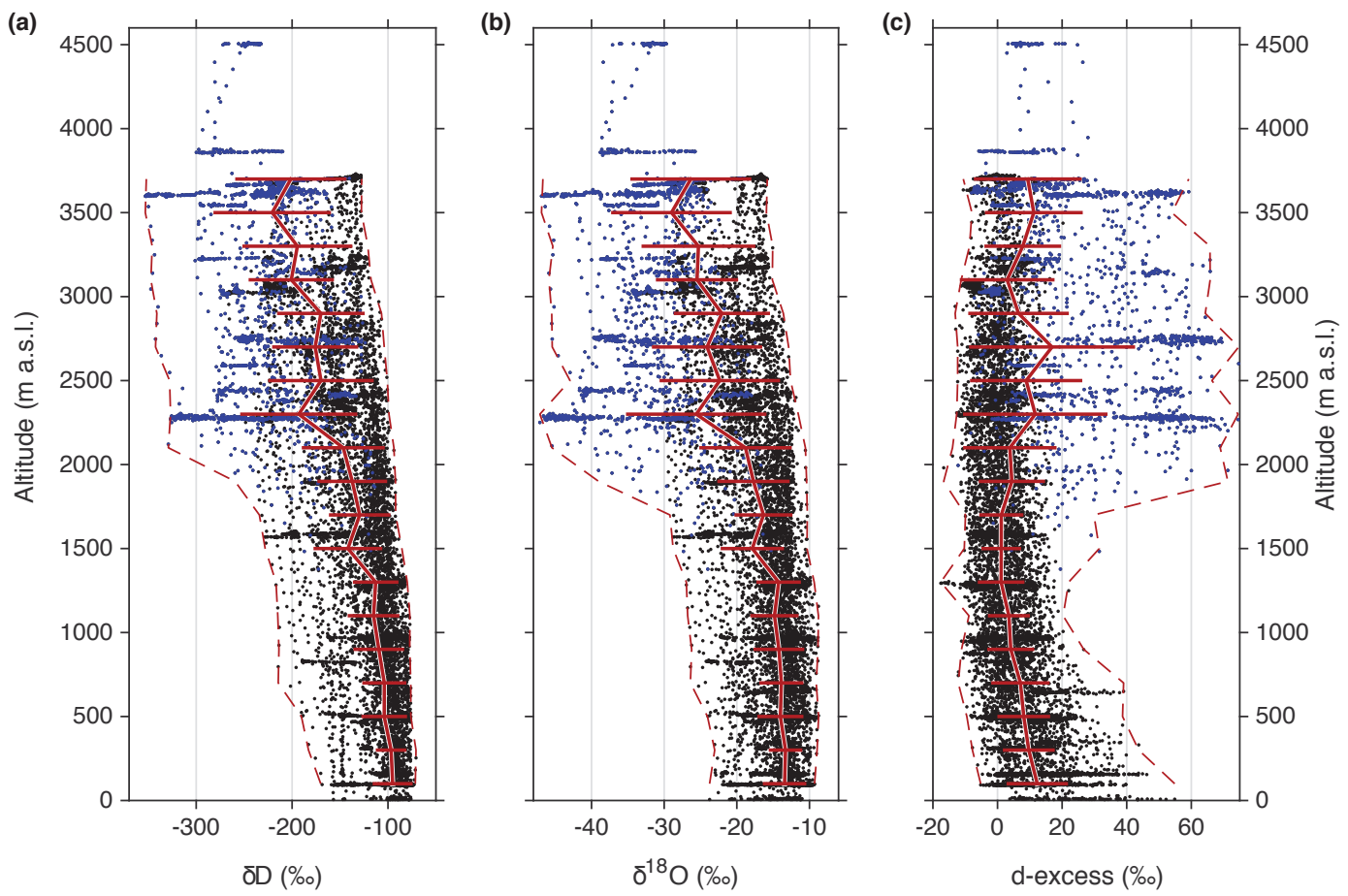

Figure 4. Vertical profiles of the isotopic composition of ambient water vapour for all valid flight data acquired during the campaign. Overlaid are $200 \mathrm{~m}$ binned mean (red solid line) and $200 \mathrm{~m}$ binned minimum and maximum values (dashed red lines) of (a) $\delta \mathrm{D},(\mathbf{b}) \delta^{18} \mathrm{O}$, and $(\mathbf{c}) \mathrm{d}-$ excess. Data points with a specific humidity below $2 \mathrm{~g} \mathrm{~kg}^{-1}$ are shown in blue. Bin averages do not extend above $3700 \mathrm{~m}$ because of low data coverage. 

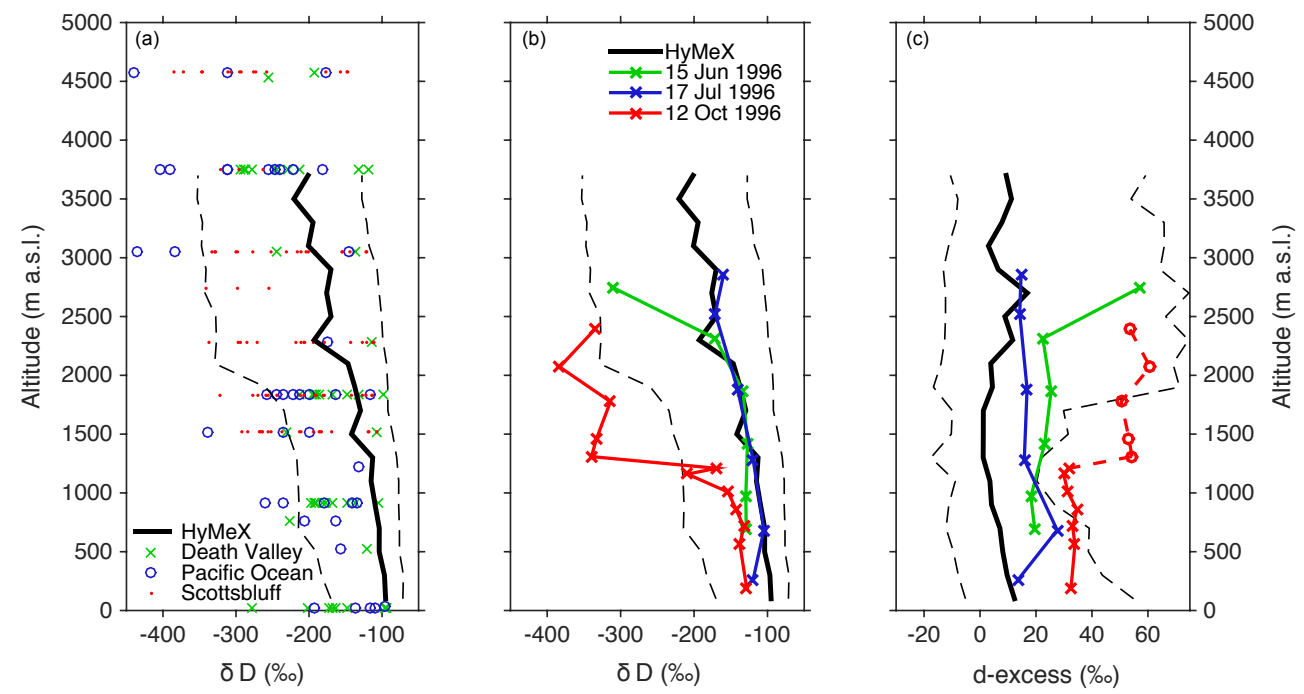

Figure 5. (a) Comparison of HyMeX measurements of $\delta \mathrm{D}$ (mean and range, black lines) to airborne $\delta \mathrm{D}$ data by Ehhalt (1974) and Ehhalt et al. (2005) from repeated flights over Death Valley, California (green crosses), the Pacific Ocean off the coast of California (blue circles), and Scottsbluff, Nebraska (red dots). (b) Comparison of HyMeX measurements of $\delta \mathrm{D}$ and (c) d-excess (mean and range, black lines) to flight measurements by He and Smith (1999) over New England forests on 15 June 1996 (green), 17 July 1996 (blue), and 12 October 1996 (red). Red circles and dashed lines denote data points for which He and Smith (1999) estimated the d-excess from all other measurements due to low-humidity conditions.

HyMeX data (Fig. 5a, black dashed lines) and the Ehhalt data for the samples above Scottsbluff, Nebraska (Fig. 5a, red dots; no data below $1500 \mathrm{~m}$ a.s.l.). The HyMeX data are more depleted above $2000 \mathrm{~m}$ a.s.l. than their measurements over the Pacific Ocean but agree well at lower altitudes (Fig. 5a, blue circles). In comparison to Death Valley, California, the HyMeX data were generally more enriched near the surface and showed a lesser gradient with height, reflecting more well-mixed conditions above the desert (Fig. 5a, green crosses).

He and Smith (1999) reported the isotopic composition of trap-collected water vapour from three flights over the forests of New England (Fig. 5b and c). For the $\delta \mathrm{D}$, there is generally good correspondence between their data points from the two summer flights (Fig. 5b, blue and green lines) and the average HyMeX profile (thick black line). The d-excess data fit within the envelope of the HyMeX data (Fig. 5c). Note, however, that because of the low humidity, He and Smith (1999) estimated the upper part of the red profile from all other measurements during their flights. Overall, the HyMeX data are thus in good correspondence with previously acquired tropospheric aircraft data, both in terms of the range and vertical variability, while adding a large amount of information on the shorter timescales and smaller spatial scales. In the next section, we attempt an interpretation of the HyMeX stable isotope data in terms of processes shaping the observed vertical structures.

\section{Processes shaping the observed mean profiles}

We now explore two hypotheses on how the observed mean isotope profiles could have been caused. The composite profiles (Fig. 4) likely reflect the substantially different isotopic composition of water vapour in the (mostly marine) boundary layer and the depleted free troposphere above. An earlier interpretation of the vertical gradient of the stable isotopes is based on the increasing depletion due to a Rayleigh fractionation process (Gedzelman, 1988; Rozanski and Sonntag, 1982). Thereby, fractionation during a moist adiabatic ascent leads to progressive depletion higher up in the atmosphere, as can be described in terms of a simple model. The mean values in the free troposphere (blue values above $1700 \mathrm{~m}$ a.s.l.) decrease in line with what can be expected from Rayleigh fractionation (see below). Alternatively, adopting an air mass mixing perspective, the maximum values of the primary isotope parameters could reflect the end member of water vapour from the sea surface, close to equilibrium conditions, which due to typically well-mixed conditions is almost constant up to $1200 \mathrm{~m}$ a.s.l. The slowly decreasing maximum values above are then a result of the (increasingly less likely) detrainment of such end-member boundary-layer air to the free troposphere and vice versa. The minimum values of $\delta \mathrm{D}$ and $\delta^{18} \mathrm{O}$ above $1700 \mathrm{~m}$ a.s.l. would then reflect air masses of a different, higher-elevation origin, for instance due to descending air masses. Then, the low values below $1700 \mathrm{~m}$ a.s.l. might reflect entrainment and mixing of such depleted water vapour into the boundary layer. As descending air masses are typically dry, the impact on the isotope composition will be 
lower during downward mixing than upward mixing. This is in agreement with the larger vertical gradient of the minimum values in the boundary layer compared to the maximum values. The plausibility of these two hypotheses is further investigated in the following sections.

\subsection{Specific-humidity dependence of $\delta \mathrm{D}$}

One way to display the additional information contained in the stable isotopes is the $\delta \mathrm{D}-q$ diagram (e.g. Noone, 2012). The data cloud in the $\delta \mathrm{D}-q$ diagram using all valid HyMeX data (Fig. 6a) can be interpreted as the range of different Rayleigh fractionation regimes the moist air experienced (e.g. Rozanski and Sonntag, 1982; Worden et al., 2007). Initially, the boundary-layer air below $1700 \mathrm{~m}$ a.s.l. (blue and red data points) is quite moist $\left(\sim 10-20 \mathrm{~g} \mathrm{~kg}^{-1}\right)$ and ranges mostly between -100 and $-70 \%$ ofor $\delta \mathrm{D}$ and is in isotopic equilibrium with a source $\delta \mathrm{D}$ of $0 \%$ at sea surface temperatures (SSTs) between 8 and $33^{\circ} \mathrm{C}$, with an average of $21^{\circ} \mathrm{C}$. This matches with typical SST observations around Corsica obtained from the IR surface thermometer (e.g. $23.0 \pm 4.7^{\circ} \mathrm{C}$ during flight 09). The increasing depletion of the data with decreasing specific humidity could then reflect a typical equilibrium fractionation pathway expected from a moist adiabatic condensation process (the canonic Rayleigh fractionation; e.g. Gat, 1996). The dashed lines in Fig. 6a show some Rayleigh processes starting at different initial conditions. The Rayleigh process, however, requires saturated moist adiabatic ascent, without exchange with the surroundings, a condition hardly observed during the mostly cloud-free HyMeX campaign period. Furthermore, the Rayleigh fractionation lines seem to follow too steep a depletion pathway compared to apparent lines in the data set that connect the more and less depleted data points in Fig. 6a.

An alternative interpretation of the $\delta \mathrm{D}-q$ diagram is to consider these apparent curves as mixing lines between two end members of different isotopic composition (Noone, 2012). Then, one end member is the free-troposphere air with low specific humidity and strong depletion and the other is boundary-layer air with high specific humidity and weak depletion. Different blends due to vertical mixing processes then produce bent mixing lines in the $\delta \mathrm{D}-q$ diagram. Such mixing lines are shown by the solid curves in Fig. 6a. As an example, the detrainment of isolated plumes of moist air with a typical specific humidity of $12 \mathrm{~g} \mathrm{~kg}^{-1}$, forced upward by ascent over the steep topography of Corsica, and subsequent mixing at a ratio of $1: 6$ with a dry and depleted end member (for example, $q=2 \mathrm{~g} \mathrm{~kg}^{-1} ; \delta \mathrm{D}=-250 \%$ ) will provide an air mass with $3.4 \mathrm{~g} \mathrm{~kg}^{-1}$ specific humidity and $-168 \% \circ \delta \mathrm{D}$.

Three arbitrary mixing scenarios are shown as solid coloured curves in Fig. 6a that could explain a large share of the data. When a relatively dry and moderately depleted air mass $\left(5.0 \mathrm{~g} \mathrm{~kg}^{-1} ;-200 \%\right.$ ) is repeatedly mixed with an equal volume of moister and less depleted boundary-layer air $\left(16 \mathrm{~g} \mathrm{~kg}^{-1} ;-90 \%\right)$, the solid black mixing line results. This mixing line is a lower-right (depleted $\delta \mathrm{D}$ and high humidity) bound to most of the blue and red data points and represents shallow mixing within the lowermost $1700 \mathrm{~m}$ a.s.l. The solid orange line has a boundary-layer end member with $-80 \%$ o $\delta \mathrm{D}$ and $15.0 \mathrm{~g} \mathrm{~kg}^{-1}$ specific humidity and a free-troposphere end member at $-300 \%$ and $1.0 \mathrm{~g} \mathrm{~kg}^{-1}$. This mixing line provides an upper-right bound (enriched $\delta \mathrm{D}$ and high humidity) to the low-elevation data (blue and red data points), which would result from mixing with free-troposphere air.

The black data points measured above $1700 \mathrm{~m}$ a.s.l. generally cover drier conditions and stronger isotopic depletion. The solid green curve shows an exemplary mixing line resulting from a moist and less depleted end member in the upper boundary layer $\left(8.0 \mathrm{~g} \mathrm{~kg}^{-1} ;-100 \%\right.$ ) and a very dry and depleted free-tropospheric air mass $\left(0.5 \mathrm{~g} \mathrm{~kg}^{-1} ;-220 \%\right.$ o). The depleted end member of the green mixing line cannot be explained by a Rayleigh model for surface conditions encountered within our data set (specific humidity at the surface $>5 \mathrm{~g} \mathrm{~kg}^{-1}$ and $\delta \mathrm{D}>-140 \%$ ). While this curve explains some of the most enriched low-humidity values, many other combinations are possible. In general, this analysis shows that a substantial part of the data can be explained by two kinds of mixing processes: one taking place between moisture originating from surface evaporation and the boundary layer and one between moderately depleted and moist air from the upper boundary layer which is entrained into the dry free troposphere.

While our measurements were done almost exclusively in unsaturated conditions, fractionation during Rayleigh-type condensation processes is obviously required to obtain depleted end members in the first place. However, this depletion process during a moist adiabatic ascent can have taken place far away, for example in tropical deep convection or ascent in a warm conveyor belt related to an extratropical cyclone, before being advected to the Mediterranean free troposphere (see Sect. 7).

\subsection{Specific-humidity dependence of the d-excess}

A similar analysis can be done for the non-equilibrium fractionation indicator d-excess. The cloud of all valid HyMeX measurement data can be separated into three regions with different characteristics (Fig. 6b). The d-excess measurements acquired between 500 and $1700 \mathrm{~m}$ a.s.l. are located in a regime of high specific humidity with a mean of about $6 \mathrm{~g} \mathrm{~kg}^{-1}$ (blue data points). In this range, d-excess averages at about $0-10 \%$, but with distinct excursions into much higher values as shown by the bin average (black line). The red points show d-excess measurements acquired below $500 \mathrm{~m}$ a.s.1. Here, d-excess ranges between 0 and $40 \%$. Many of the high d-excess values were acquired at lowelevation transects over the ocean, thus likely representing the imprint of the non-equilibrium fractionation conditions due to the low relative humidity with respect to SST during evaporation. 

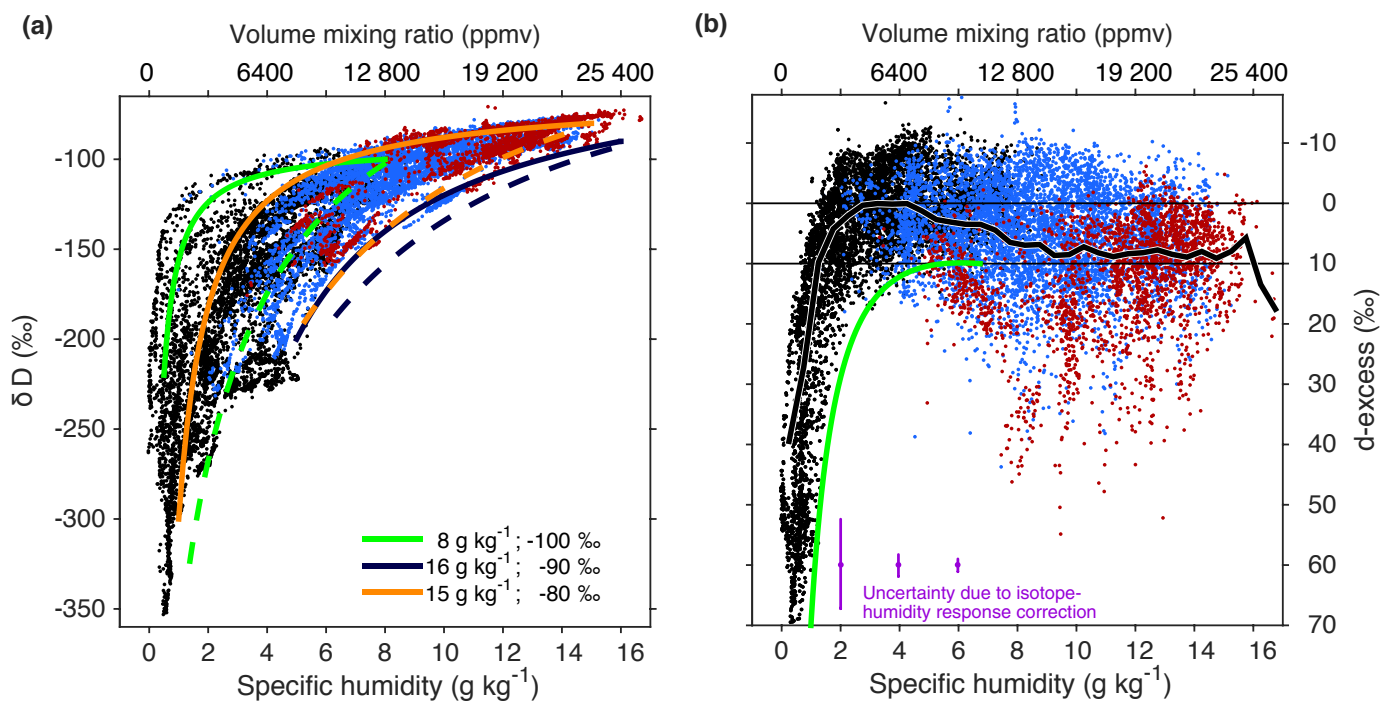

Figure 6. Scatter diagrams of (a) $\delta \mathrm{D}\left(\%\right.$ ) and (b) d-excess $(\% \circ)$ versus specific humidity $q\left(\mathrm{~g} \mathrm{~kg}^{-1}\right)$. Shown are $30 \mathrm{~s}$ averaged data from all valid flights. Data points acquired below 500 (1700) $\mathrm{m}$ a.s.l. are marked in red (blue). Coloured curves in (a) represent idealized mixing (solid lines) and Rayleigh fractionation processes (dashed lines) as described in the main text. Upper $x$ axis gives water concentration in units of parts per million by volume for easier comparison with other published studies. Green line in (b) represents d-excess from a Rayleigh fractionation process. Black line in (b) is a bin average. Purple points with error bars show the uncertainty resulting from the isotope-humidity response correction at different humidity levels. Note that the d-excess axis in (b) is inverted for display purposes.

The branch of free-troposphere measurements (> 1700 ma.s.l.; Fig. 6b, black dots) extends from a dexcess of about $0 \%$ at $\sim 5 \mathrm{~g} \mathrm{~kg}^{-1}$ to progressively higher, values of up to $60 \%$ as the specific humidity decreases to below $0.5 \mathrm{~g} \mathrm{~kg}^{-1}$. As noted in Sect. 2, the uncertainty of the d-excess data beyond this value is strongly enhanced by the correction for the humidity dependence of the CRDS isotope measurements (Fig. 6b, purple bars). It is noteworthy that almost all measurements at low humidity have high d-excess values and that there is an apparently seamless transition from high d-excess at below $2 \mathrm{~g} \mathrm{~kg}^{-1}$ to lower d-excess at $2-4 \mathrm{~g} \mathrm{~kg}^{-1}$. In addition to the arguments brought forward in Sect. 3, this further supports our interpretation of the high and increasing d-excess as an actual geophysical signal.

The solid green line in Fig. 6a shows the d-excess expected from a Rayleigh fractionation process starting at $10^{\circ} \mathrm{C}$ surface air temperature and an isotopic composition of $\delta \mathrm{D}=-86 \%$ and $\delta^{18} \mathrm{O}=-12 \%$ (d-excess $=10 \%$ ). The shape of the curve illustrates that equilibrium fractionation can strongly impact the d-excess due to the different temperature dependency of the fractionation factors (e.g. Duetsch et al., 2017 Sodemann et al., 2008a). Note that the displayed green line provides an upper bound to the increase in dexcess with decreasing humidity. Mixing processes generally seem to act towards lowering the d-excess relative to that upper bound.

The combination of the high d-excess in the free troposphere and the data points influenced by surface evaporation produce an apparent minimum of the d-excess at $\sim 4 \mathrm{~g} \mathrm{~kg}^{-1}$, in correspondence with the vertical profile (Fig. 4c). In addition, there are many data points with d-excess below $0 \%$, mostly at specific humidity between 2 and $8 \mathrm{~g} \mathrm{~kg}^{-1}$. Negative d-excess in water vapour can be due to the evaporation of rainfall or from continental moisture sources due to strong soil evaporation. During evaporation, the d-excess of raindrops is reduced (Aemisegger et al., 2015), while a relatively enhanced d-excess is transferred to the surrounding vapour. When these droplets evaporate completely, however, they cause a negative imprint on the surrounding vapour(e.g. Gat, 1996). Evaporating rainfall or dissolving (evaporating) clouds could thus create a vertical gradient of d-excess in vapour under certain conditions. Thereby, vapour with decreasing d-excess is contributed to the environment as more of the raindrops evaporate during their fall. We speculate that near the boundary-layer top, the contribution of rainfall and cloud evaporation to the vapour is largest. One could, for example, conceive of a situation where boundary-layer top cumuli locally produce rainfall in a saturated environment, whereas evaporation occurs in the immediate vicinity and below the cloud in regions influenced by dry-air entrainment from the free troposphere above. Being relatively far away from the high d-excess created during surface evaporation, this combination of processes could potentially shape an overall d-excess minimum in the vertical profiles. The predominance of d-excess values close to $10 \%$ as in the global meteoric water line, rather than the occasional high values representing enhanced non-equilibrium fractionation during evaporation, suggests that overall evaporation conditions at 
the moisture sources were not characterized by strong nonequilibrium conditions or that newly evaporated water contributed comparatively little to the available moisture in the boundary layer. In our data set, the high d-excess signal from local, short-lived intense evaporation events thus seems to disperse with altitude. Benetti et al. (2014, 2015) highlight the importance of mixing processes between surface vapour and the free troposphere in the marine boundary layer. From analysing ship-based isotope measurements in the subtropical east Atlantic with an idealized model, Benetti et al. (2015) conclude that mixing with free-troposphere air is more important for the primary isotope parameters than for d-excess, which is mainly controlled by non-equilibrium effects during evaporation, a finding that may be specific to evaporationdominated situations. In this comparison, it is important to note that the lowest measurement altitude of the aircraft was at $150 \mathrm{~m}$ a.s.1., making direct comparison to ship-based measurements difficult. Gat et al. (2003) even noted a vertical isotope gradient for different measurement altitudes on a ship. Thus, the influence of the free troposphere at our lowest measurement altitude may already be higher than for ship-based measurements. This also points to deviations from the wellmixed conditions of the isotopic composition in the marine boundary layer assumed above.

\section{Evolution of the vertical stable isotope structure on several days in sequence}

The contrast between weakly depleted water vapour in the boundary layer and moderately to strongly depleted water vapour in the free troposphere is further explored now by considering the atmospheric environment and airborne measurements during specific flights. As will be exemplified below, diurnal variability and larger-scale processes jointly shape the vertical stratification reflected in the isotope profiles.

A sequence of three flights was executed following pattern 3 (Fig. 1) between 20 and 21 September 2012 (flights 09-11). The pattern consisted of several east-west transects across the island, a low-level leg over the sea to the west, and vertical profiles over the island and to the east and west of it (Fig. 8a, white line; Fig. 1, green line). The vertical profile northwest of Corsica was also included in pattern 1 , which was flown after the sequence, on 23 September 2012 (flight 12). This sequence of flights allows for investigating the development of the vertical isotope profiles for four flights and on 4 days. The period from 20 to 23 September 2012 was marked by pronounced differences in the vertical stratification of the lower and middle troposphere. On 20 September, ex-Hurricane Nadine was located at the upstream side of an upper-level ridge near $30^{\circ} \mathrm{W}$ and $35^{\circ} \mathrm{N}$, in close proximity to an equatorward extending potential vorticity streamer (Fig. 7, thick black contour). Interaction between these two dynamical features determined the synoptic

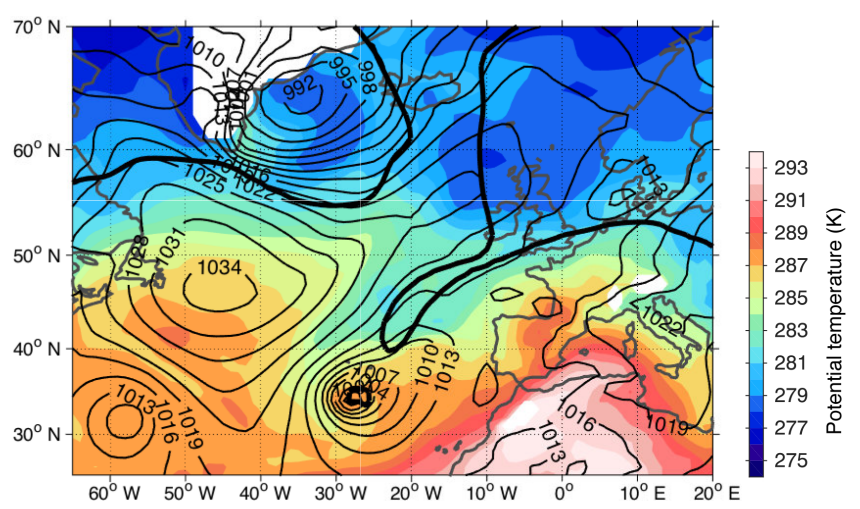

Figure 7. Weather situation at 12:00 UTC, 21 September 2012 (flights 09-11). Shown are sea level pressure (black lines, $3 \mathrm{hPa}$ contour interval), equivalent potential temperature at $850 \mathrm{hPa}$ (colour shading, $1 \mathrm{~K}$ interval), and the tropopause structure depicted by a contour of two potential vorticity units on the $315 \mathrm{~K}$ isentrope (thick black line) from ECMWF analysis data.

evolution over the western Mediterranean during the following days.

Initially, the eastern flank of a large upper-level ridge was located over Corsica, leading to the advection of air masses from the northwest with wind speeds of $\sim 16 \mathrm{~ms}^{-1}$ on $500 \mathrm{hPa}$ (Fig. 8a, white arrows; Fig. 7, black contour). Central Europe was under the influence of a high-pressure system, and the Mediterranean experienced intermediate temperatures, with $282-286 \mathrm{~K}$ on $850 \mathrm{hPa}$ (Fig. 7, colour shading). The region of interest was almost cloud-free (Fig. 8a, shading). Winds were from northerly directions with speeds of about $7 \mathrm{~m} \mathrm{~s}^{-1}$ on $700 \mathrm{hPa}$ and associated with cold-air advection throughout the lower troposphere (Fig. 8a, red arrows). During the first flight of this sequence (flight 09) at 20 September 2012, a vertical profile was flown at the northwest end of flight pattern 3, west of Corsica over the Mediterranean Sea (Fig. 8a, cyan line).

Figure 9a-d displays the temperature, specific humidity, and the stable isotope parameters at the vertical profile during flight 09 . The temperature profile depicts two pronounced inversions between 900-1000 and 2300-2500 m a.s.1., which are well reproduced during ascent and descent (Fig. 9a, black and grey lines). The boundary layer below $900 \mathrm{~m}$ a.s.l. and the layer above $2500 \mathrm{~m}$ a.s.1. are both well-mixed, with uniform lapse rates of 7.3 and $6.0 \mathrm{~K} \mathrm{~km}^{-1}$, respectively. The intermediate layer has a lapse rate of $-7.6 \mathrm{~K} \mathrm{~km}^{-1}$ and an approximately isothermal lower end that shows enhanced temperature variability. The profile of specific humidity shows changes corresponding to the observed thermal structure (Fig. 9b). The boundary layer has a specific humidity of 9-11 $\mathrm{g} \mathrm{kg}^{-1}$, which drops to substantially lower values (3$5 \mathrm{~g} \mathrm{~kg}^{-1}$ ) at and above the capping inversion. As for temperature, humidity variations are enhanced between 1000 and $1700 \mathrm{~m}$ a.s.l., possibly related to the partial cloud cover ob- 
(a)

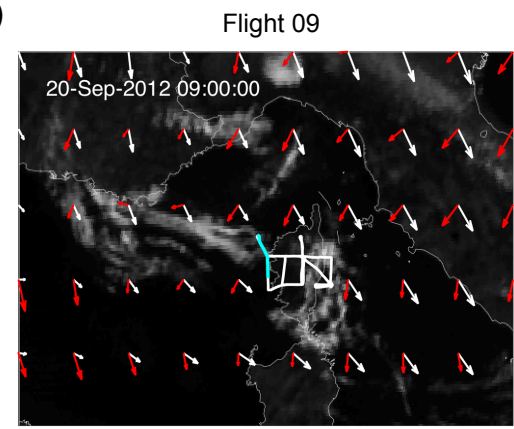

(b)

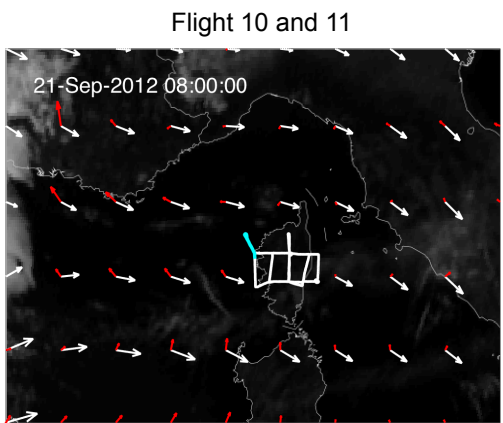

(c)

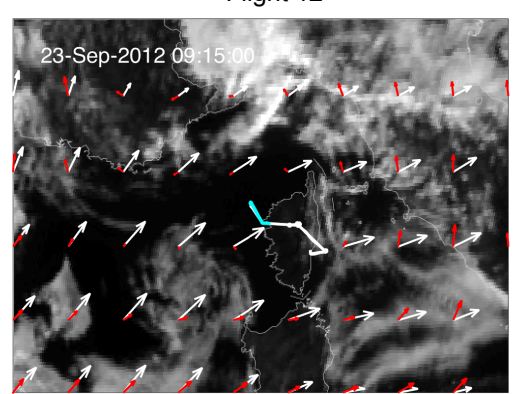

Figure 8. Cloudiness and winds at (a) 09:00 UTC, 20 September 2012, during flight 09, (b) 09:00 UTC, 21 September 2012, during flights 10 and 11, and (c) 09:00 UTC, 23 September 2012, during flight 12. Shown is Meteosat 9 infrared imagery with flight track (white line) and aircraft position during the profiles (cyan line) with ECMWF analysis winds at $500 \mathrm{hPa}$ (white arrows) and $925 \mathrm{hPa}$ (red arrows) overlayed.

served in the satellite image (relative humidity reached $90 \%$ between 600 and $900 \mathrm{~m}$ a.s.l.). Specific humidity drops to uniformly very low values $\left(1-2 \mathrm{~g} \mathrm{~kg}^{-1}\right)$ at the upper inversion. Some difference between the upward and downward profile is apparent for humidity (Fig. 9b, black and grey lines).

The vertical profile of $\delta \mathrm{D}$ (Fig. 9c) in turn corresponds to the humidity profile. In the boundary layer, values of weak depletion $(-90$ to $-100 \% \circ \delta \mathrm{D})$ reflect proximity to the evaporation source. At the capping inversion ( $900 \mathrm{~m}$ a.s.l.) $\delta \mathrm{D}$ drops to $-150 \%$, with increased variability. Above $1700 \mathrm{~m}$ a.s.l. $\delta \mathrm{D}$ increases again to $-120 \%$ o. This isotopic inversion together with the specific humidity information confirms that the layer between 1000 and $2300 \mathrm{~m}$ actually consists of two layers of different origin or air mass history. Without the isotope measurements this distinction could hardly be made. Repeatability is lower for the upward and downward profiles for $\delta \mathrm{D}$, in particular above $2300 \mathrm{~m}$ a.s.l. The downward profile (black line) is expected to be more reliable, as memory effects are smaller when moving from dry to moister conditions during descent (Appendix A4). Note that the coherent variability across the three available specific-humidity measurements point to at least a partial contribution from spatial variability (not shown). A further influence may come from the pressure dependency of the CRDS measurements during upward and downward motion of the aircraft (Appendix A5).

The shape of the d-excess profile (Fig. 9d) does not reflect the thermodynamic structure observed in temperature and humidity. In the lowermost $300 \mathrm{~m}$ a.s.l. values of up to $40 \%$ are measured for the d-excess. This likely reflects nonequilibrium fractionation during intense evaporation in the marine surface layer at the aircraft location or upstream. As a proxy for the d-excess during evaporation, relative humidity with respect to SST $\left(\mathrm{RH}_{\mathrm{SST}}\right)$ has been calculated from $q_{\mathrm{HCLY}}$ at flight altitude and the skin temperature measured from the infrared radiometer (Table 1). The observed d-excess of $\sim 30 \%$ o corresponds to an $\mathrm{RH}_{\mathrm{SST}}$ of $\sim 40 \%$ (Pfahl and Sode- mann, 2014), slightly lower than the measurements along a low-level transect immediately following the profile $\left(\mathrm{RH}_{\mathrm{SST}}\right.$ of $\sim 48 \%$ at $150 \mathrm{~m}$ a.s.1.; Table 4 , second row). It is noteworthy that the SST is more than $5 \mathrm{~K}$ warmer than the air temperature at $150 \mathrm{~m}$ a.s.l., which suggests that the at the elevation of the aircraft measurements, the atmosphere may not yet be fully coupled to the surface conditions at this time of day. Nonetheless, the d-excess indicates strong non-equilibrium fractionation conditions at the underlying sea surface during intense evaporation. The d-excess decreases to $\sim 15 \%$ o in the layer between 300 and $1500 \mathrm{~m}$ a.s.l. and shows values near $10 \%$ between 1500 and $2300 \mathrm{~m}$ a.s.l., before increasing to more than $60 \%$ at the highest part of the profile. The d-excess is fairly well reproduced for the upward and downward profile, with most pronounced differences in the very dry part of the profile above $2300 \mathrm{~m}$ a.s.l.

The same flight pattern was repeated $23 \mathrm{~h}$ later during flight 10 on 21 September 2012 (Fig. 8b). The large-scale circulation remained very similar to the previous flight (Fig. 7). Around Corsica, a weak southeasterly flow advected drier air towards the island at lower-troposphere levels and reduced cloudiness (Fig. 8b). Upper-level winds had strengthened and turned to westerly directions. The vertical profile of temperature had changed considerably, now showing an inversion between 1700 and 2200 ma.s.l. (Fig. 9e). The upper layer had warmed by about $3 \mathrm{~K}$ and dried uniformly to a specific humidity of $1-2 \mathrm{~g} \mathrm{~kg}^{-1}$ (Fig. 9f). The vertical contrasts in the isotopic composition had increased markedly. Below the inversion $\delta \mathrm{D}$ was slightly more depleted compared to $23 \mathrm{~h}$ before $(-110$ to $-120 \%$; Fig. $9 \mathrm{~g})$. This is rather different from equilibrium with the given SST $(\delta \mathrm{D}=-80 \%$ for an SST of $\sim 20^{\circ} \mathrm{C}$ ), even though the sea surface had cooled by $\sim 6 \mathrm{~K}$ (Table 4). Across the inversion, the $\delta \mathrm{D}$ decreased to $-380 \%$ within only $300 \mathrm{~m}$ vertically during the downward profile (Fig. 9g, solid line). At the highest elevations (3700$3300 \mathrm{~m}$ a.s.l.) the $\delta \mathrm{D}$ profile showed very good reproducibility of the upward and downward profiles with about $-250 \%$ o depletion. The d-excess profile had a similar shape as during 

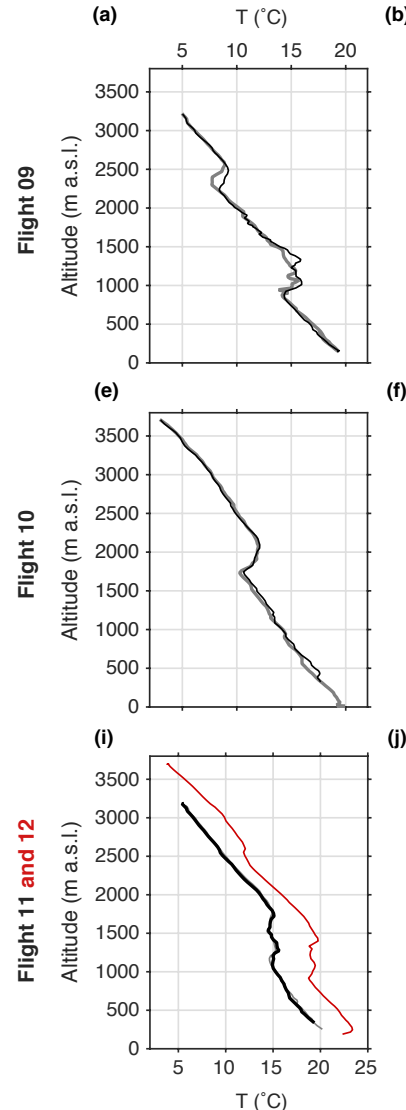

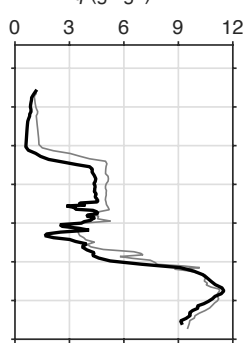

(f)

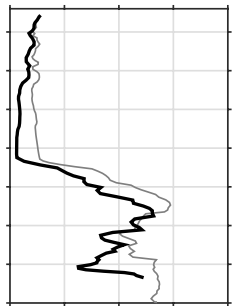

(j)

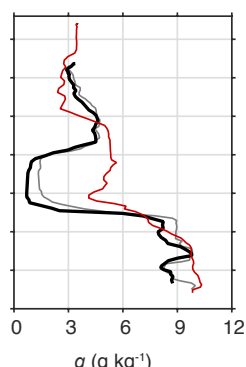

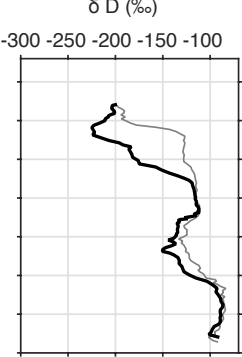

(g)

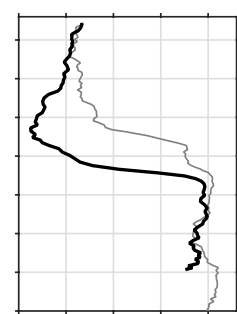

(k)

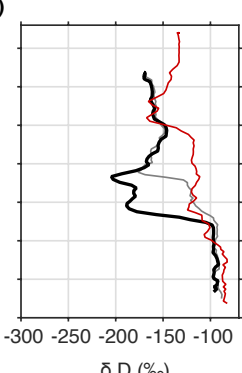

(d)

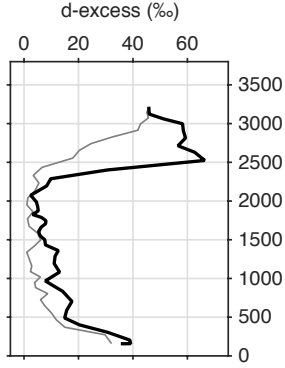

(h)

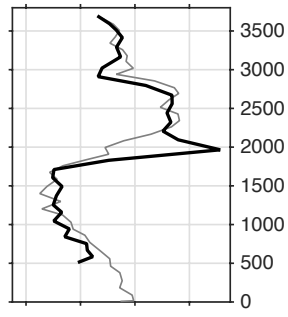

(I)

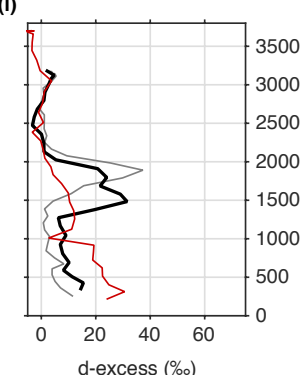

Figure 9. Vertical profiles of air temperature $\left(T,{ }^{\circ} \mathrm{C}\right.$; first column), specific humidity $\left(q, \mathrm{~g} \mathrm{~kg}^{-1}\right.$; second column), $\delta \mathrm{D}(\% \circ$; third column), and the d-excess (\%; fourth column) for flights 09-12 conducted during 21-23 September 2012. Only downward profiles are shown as they are less affected by memory than upward profiles. Red lines in panels (i) to (l) show the downward profile acquired during flight 12.

the previous flight, albeit at lower elevation, and agreed very well for both profiles (Fig. 9h). A minimum d-excess of about $10 \%$ was measured just below the temperature inversion at $\sim 1700 \mathrm{~m}$.

The flight pattern was repeated a third time another $3.5 \mathrm{~h}$ later during flight 11 (11:00-15:00 UTC, 21 September 2012) with largely unchanged large-scale circulation and winds around Corsica (not shown). The temperature inversion had descended to $1400 \mathrm{~m}$ a.s.l. (Fig. 9i). Contrasts in specific humidity were very pronounced (Fig. 9k), with a moister boundary layer than during flight $10\left(\sim 9 \mathrm{~g} \mathrm{~kg}^{-1}\right.$; compare Fig. 9f), a very dry intermediate layer $\left(1 \mathrm{~g} \mathrm{~kg}^{-1}\right)$, and a moderately moist upper layer $\left(3-4 \mathrm{~g} \mathrm{~kg}^{-1}\right)$. The drastic humidity difference between the two lowermost layers was also apparent in the $\delta \mathrm{D}$ profile, with a jump from -100 to $-200 \%$ within about $200 \mathrm{~m}$ vertical distance (Fig. 9k). Reproducibility was very good for this $\delta \mathrm{D}$ profile, except for the dry intermediate layer, which indicates possible memory effects in the inlet system when entering from humid into dry air layers. The d-excess showed quite a different profile for this flight with values of up to $30 \%$ in the dry layer (Fig. 91). Possibly, low d-excess water vapour from the surrounding may have reduced the d-excess by entrainment. The absence of a clear maximum near the bottom indicates that high RH conditions (70-80\%) and weak evaporation prevailed in this situation (d-excess of $\sim 14 \%$ ).

Another $36 \mathrm{~h}$ later, during the final flight in this sequence (flight 12 at 09:00 UTC, 23 September 2012), the potential vorticity streamer in the large-scale circulation had evolved into a cut-off with rapid cyclogenesis near the Bay of Biscay, leading to the advection of air with high equivalent potential temperature from the Sahara to the western Mediterranean (not shown). Southwesterly flow dominated throughout the troposphere, associated with widespread broken cloud cover (Fig. 8c). The single downward vertical profile available on 23 September 2012 shows that the vertical structure of the boundary layer had changed significantly in all variables (red profiles in Fig. 9i-1). Temperature had increased by about 2 $3 \mathrm{~K}$ and the layer above $1500 \mathrm{~m}$ a.s.l. had moistened significantly, leading to the observed cloudiness. The $\delta \mathrm{D}$ profile had shifted to uniformly less depleted conditions of around $-140 \%$ above $1400 \mathrm{~m}$ a.s.l, while the d-excess gradually decreased from values around $20-30 \%$ below $500 \mathrm{~m}$ a.s.l. towards about $0 \%$ at the top of the profile. 
Table 4. Mean and standard deviation of meteorological and isotopic parameters measured during the low-level transects over open water during flights 09-11 as part of flight pattern 3. (a) Values are mean and standard deviation of $15 \mathrm{~s}$ mean data of the parameters WD (wind direction), WS (wind speed), and RH (relative humidity). (b) As (a), but for the parameters $\mathrm{RH}_{\mathrm{SST}}$ (relative humidity with respect to SST), $\mathrm{SST}$, and the isotopic parameters $\delta^{18} \mathrm{O}, \delta \mathrm{D}$, and d-excess.

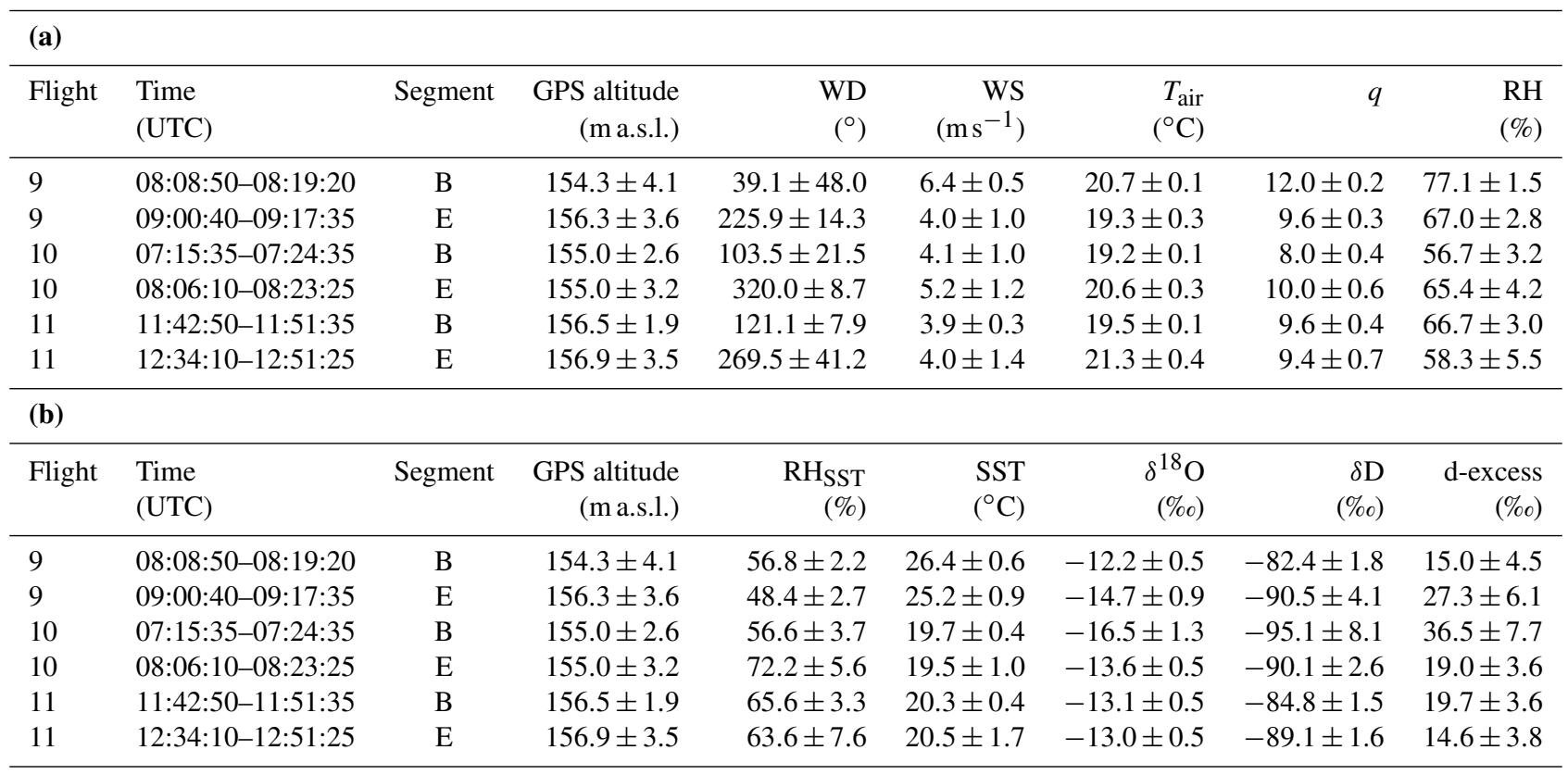

The temporal variability of the vertical structure of the isotopic composition observed above has implications for the relative importance of vertical mixing and large-scale advection for understanding the vertical profiles. It appears that the two processes go hand in hand: the inversions delineate layers that are internally well-mixed but evidently have weak mixing across the inversion. Inversions thus also separate layers with a very different origin and transport history. The combination of the two can lead to strongly variable and well-structured vertical profiles as observed during the HyMeX flights, which show surprisingly strong day-to-day variability also in a situation where the large-scale conditions are seemingly rather similar. One implication of this is that a single vertical profile in a high-pressure situation might not be representative of this weather situation. The presence of the complex topography around Corsica with various influences in upstream and downstream regions further complicates the situation. The strongest isotope gradient and temperature inversion were encountered during flight 10; the following sections discuss in more detail how stable isotopes allow interpreting the transport history of an air mass.

\section{High-resolution stable isotope measurements during flight 10 (21 September 2012)}

We now present the high-resolution horizontal and vertical variability obtained during flight 10 on 21 September 2012 (the second flight discussed in Sect. 5). During this flight clouds were almost absent, and a strong vertical wind shear prevailed, with southeasterly winds in the boundary layer and westerly winds in the free troposphere (Fig. 8b). A deep inversion of $\sim 3 \mathrm{~K}$ between 1700 and $2200 \mathrm{~m}$ a.s.l. characterized the atmospheric stratification during this flight, both at locations west (Fig. 9e) and east (not shown) of Corsica, separating a moist marine boundary layer from a very dry free troposphere (Fig. 9)

Figure 10 shows the flight altitude and meteorological and isotope parameters during the first $2.5 \mathrm{~h}$ of flight 10 (flown along pattern 3; compare Fig. 1). The flight period has been subdivided into segments $\mathrm{A}-\mathrm{H}$ in Fig. 10. During the vertical profile in segment A, the aircraft encountered a dramatically different meteorological and stable isotope composition between flight altitudes of 1500 and $2500 \mathrm{~m}$ a.s.l. At 07:00 UTC, during ascent from about 1700 to $2000 \mathrm{~m}$ a.s.l., specific humidity decreased abruptly from 8 to about $1 \mathrm{~g} \mathrm{~kg}^{-1}$ (Fig. 10c, red and black lines). Humidity was in fact below the detection limit for the dew point mirror hygrometer. Associated with the drop in specific humidity were an increase in potential temperature from 299 to $305 \mathrm{~K}$ (Fig. 10b, black line), an increase in air temperature from 10 to $12{ }^{\circ} \mathrm{C}$ (panel $\mathrm{b}$, red line), and a drop in relative humidity (Fig. 10d) from 80 to $\sim 15 \%$. Winds gradually changed from southerly to northwesterly directions and back during segment A (Fig. 10e).

The stable isotope composition shows similar strong changes across the inversion at the boundary-layer top. $\delta \mathrm{D}$ 

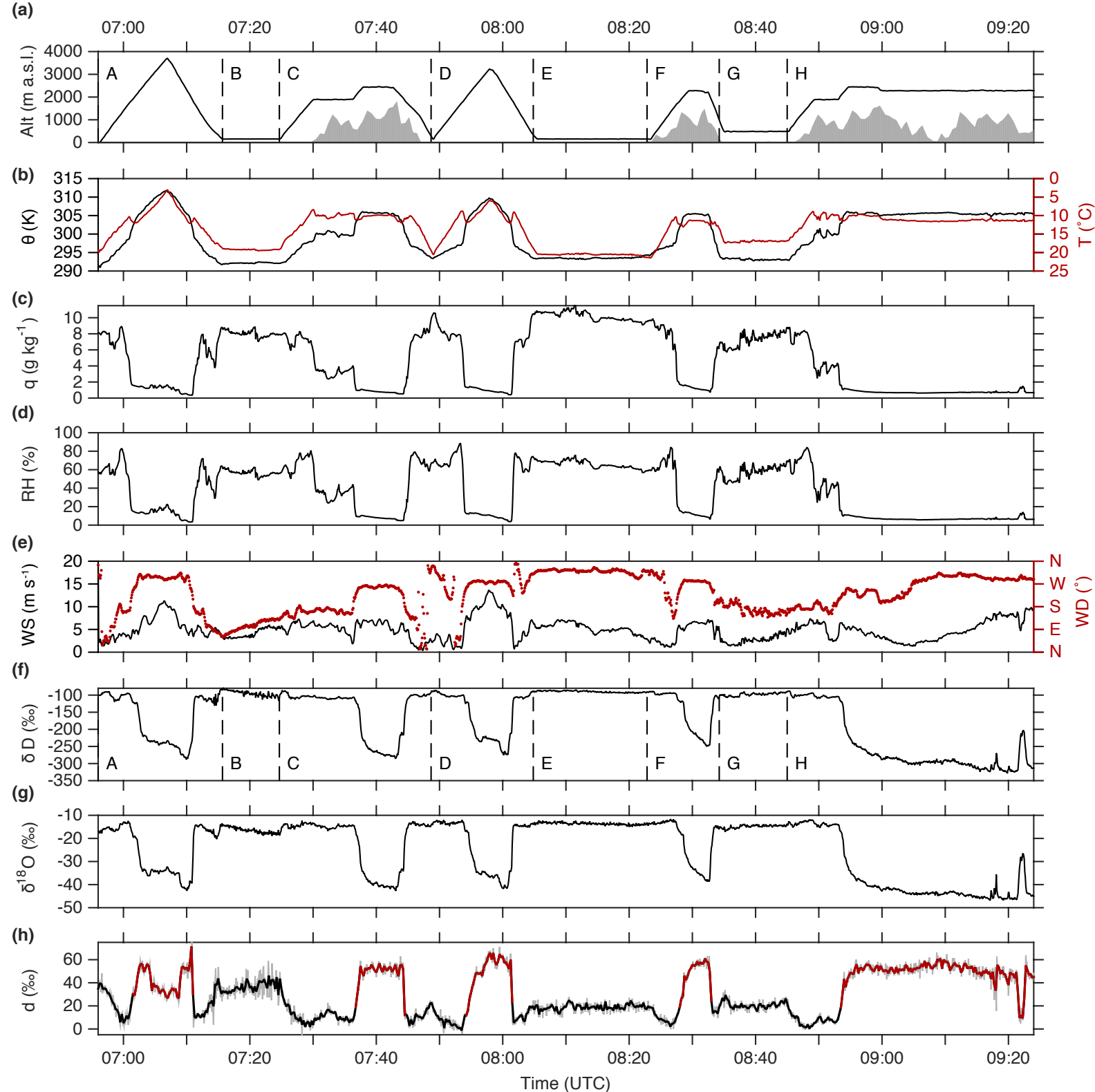

Figure 10. Segments A to H of flight 10 on 21 September 2012, 07:00-09:25 UTC. (a) Flight altitude (black line) and topography (grey

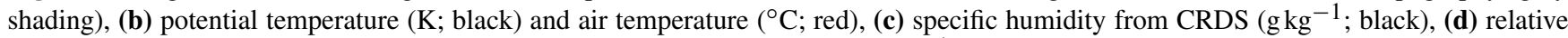
humidity from HCLY temperature and humidity (\%; black), (e) wind speed ( $\mathrm{m} \mathrm{s}^{-1}$; black) and wind direction ( ${ }^{\circ}$; red), (f) $\delta \mathrm{D}(\% \circ$; black) at $15 \mathrm{~s}$ averaging time, $(\mathbf{g}) \delta^{18} \mathrm{O}(\%$; black) at $15 \mathrm{~s}$ averaging time, (h) d-excess (\%o) at $15 \mathrm{~s}$ averaging time (grey) and $30 \mathrm{~s}$ averaging time (black). Sections highlighted in red are for specific humidity below $2 \mathrm{~g} \mathrm{~kg}^{-1}$. Labels A-H denote different sections of the flight pattern.

$\left(\delta^{18} \mathrm{O}\right)$ shows an initial drop from -100 to $-225 \%$ ( -13 to $-35 \%$ ) and then a further depletion before the re-entry into the boundary layer at 07:11 UTC with a minimum of $-275 \%$ o $\left(-41 \%\right.$ o for $\delta^{18} \mathrm{O}$ ) at the end of segment A (Fig. 10f and $\mathrm{g}$ ). The d-excess mirrors the jump of the primary isotope parameters, increasing from 12 to $65 \%$ across the inversion at 07:02 UTC (the d-excess is drawn in red for $q<2 \mathrm{~g} \mathrm{~kg}^{-1}$ ). It then decreases to about $40 \%$ for $5 \mathrm{~min}$ when the aircraft is above $3000 \mathrm{~m}$ a.s.l., before increasing again to about $55 \%$ o (the period when the primary isotope parameters are lowest), before finally returning to about $15 \%$. The d-excess thus hints at a different air mass above $3000 \mathrm{~m}$ a.s.l. at this location, which is supported by close inspection of the wind speed, relative humidity, and specific humidity. This could have been overlooked easily without considering the d-excess.

Throughout the flight, the aircraft returned four times into this dry air layer above $1700 \mathrm{~m}$ a.s.l. (Fig. 10, segments C, 
D, F, H). Very similar behaviour was observed for the meteorological and stable isotope parameters at the same altitudes. The profile at segment $\mathrm{D}$ is shown in Fig. 9e-h, and underlines the sharpness of the transition at the inversion. From the downward profiles the vertical gradient of the isotopic composition across the inversion is estimated

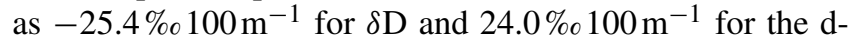
excess.

After completion of the vertical profile at Segment A, the aircraft performed a low-level leg at the minimum safe altitude (ca. $155 \mathrm{~m}$ above the surface) over open water (07:1207:25 UTC, segment B). Specific humidity and relative humidity remained narrowly at about $8 \mathrm{~g} \mathrm{~kg}^{-1}$ and $57 \%$, respectively, during this transect (Table 4). $\mathrm{RH}_{\mathrm{SST}}$ was about $57 \%$. The expected non-equilibrium fractionation conditions during evaporation do not fully correspond to the high measured d-excess of $\sim 37 \%$ (depending on the non-equilibrium fractionation factor, one would expect here $\mathrm{RH}_{\mathrm{SST}}$ to be about $18-25 \%$ according to the Craig-Gordon model) and point towards evaporation sources of at least part of the sampled water vapour elsewhere. With average wind speeds of $4 \mathrm{~m} \mathrm{~s}^{-1}$ from southeasterly directions, only weak evaporation would be expected.

A second low-level transect performed west of Corsica over the open ocean (08:05-08:25 UTC, segment E) is marked by lower d-excess of $19 \%$ compared to segment B, which was performed east of Corsica (Table 4 and Fig. 10). Specific and relative humidity are slightly higher $\left(10 \mathrm{~g} \mathrm{~kg}^{-1}\right.$ and $65 \%$, respectively), while $\mathrm{RH}_{\mathrm{SST}}$ was on average $72 \%$, matching the SST $\left(19.5^{\circ} \mathrm{C}\right)$, which was lower than air temperature $\left(20.6^{\circ} \mathrm{C}\right)$. Again, the $\mathrm{RH}_{\mathrm{SST}}$ does not explain the d-excess, and thus the main sources of the moisture measured by the aircraft may be located elsewhere (in a northwesterly direction, as indicated by the mean wind direction of $320^{\circ}$ ). Throughout the flight, the lowest values of the dexcess occur consistently at high RH conditions, at elevations where the BL (boundary-layer) top is expected, such as during segments $\mathrm{A}, \mathrm{C}, \mathrm{D}$, and $\mathrm{F}$. This points again to the role of cloud and precipitation evaporation processes in shaping the $\mathrm{d}$-excess minimum observed in the overall profile.

\section{Air mass origin and transport history}

Air mass origin and the transport history for a part of the air sampled during flight 10 are now investigated with a backward trajectory analysis using the LAGRANTO (Lagrangian Analysis Tool) model (Wernli and Davies, 1997) based on ECMWF operational analysis data at a $0.5^{\circ} \times 0.5^{\circ}$ horizontal grid spacing. Trajectories were calculated 5 days backward in time every $10 \mathrm{~s}$ along the flight track for the time interval 07:54-08:06 UTC, i.e. during the transition from the free troposphere into the boundary layer (second part of segment D; Fig. 10a). The trajectory analysis confirms a very different origin of the air masses in the two vertical layers.
In the lower troposphere (700-800 hPa), the aircraft encountered air masses that 4-5 days back in time had been located over southern Greenland (Fig. 11a, red trajectory segments) in the upper troposphere at pressure altitudes of $\sim 400 \mathrm{hPa}$ (Fig. 11b, black lines). These air masses descended gradually by $\sim 100 \mathrm{hPaday}^{-1}$ before being encountered by the aircraft. Large-scale descent of upper-tropospheric air due to its southward displacement along sloping isentropes with adiabatic warming is thus the most plausible cause for the low relative humidity observed during flight 10 . This is also supported by a trajectory analysis for flight segments A, C, and $\mathrm{F}$, which show consistent source regions and descent from similar altitudes (not shown).

The trajectories descending from high elevation were very dry $\left(0.3 \pm 0.2 \mathrm{~g} \mathrm{~kg}^{-1}\right) 4$ days before encounter and hardly moistened according to the ECMWF analysis data at $-12 \mathrm{~h}$ $\left(0.5 \pm 0.4 \mathrm{~g} \mathrm{~kg}^{-1}\right)$. These values agree well with the humidity observed by the aircraft $\left(0.4-0.7 \mathrm{~g} \mathrm{~kg}^{-1}\right.$ during the downward profile in segment D; Fig. 10c). The potential temperature of the air masses from the upper troposphere decreased due to radiative cooling by about $5 \mathrm{~K}$ during the 5 days of descent and was 303-309 K during encounter (Fig. 11c), in very good agreement with the observations (Fig. 10b). In contrast, the air mass encountered during the lower parts of segment $D$ was much more humid $\left(6 \mathrm{~g} \mathrm{~kg}^{-1}\right.$; Fig. 11a), lower than the range of the observations $\left(7-10 \mathrm{~g} \mathrm{~kg}^{-1}\right)$. Trajectory analysis shows an origin of these moist air masses over Italy, France, Corsica, and nearby areas of the western Mediterranean. The air masses gradually warmed (Fig. 11c, grey trajectories) and moistened (not shown) while being advected in the lower troposphere from the northwest during the 5 days before encounter (Fig. 11a, blue trajectory segments). This underlines that the isotope composition is related to the transport history of air masses in this situation.

Vertical cross sections using ECMWF analyses centred at Corsica approximately at the time of flight 10 (06:00 UTC, 21 September 2012) provide insight into the spatial extent of different air masses and the sharpness of the transition between the free troposphere and the boundary layer in the ECMWF model (Fig. 12). Dry air reached from the upper troposphere down to $750-850 \mathrm{hPa}$ directly over Corsica (upper white areas in Fig. 12a and b), corresponding to the downward sloping isentropic flow from the northwest along the 300 and $305 \mathrm{~K}$ isentropes. Further south, a fairly moist $(\sim 5$ $7 \mathrm{~g} \mathrm{~kg}^{-1}$ ) air mass with potential temperatures between 305 and $315 \mathrm{~K}$ was located above the dry air, and east of $6^{\circ} \mathrm{E}$ at higher elevations (above $850 \mathrm{hPa}$; Fig. 12a). This subtropical air mass associated with ex-Hurricane Nadine and the cut-off low displaced the dry upper-tropospheric air during the next 2 days, apparent also as increased cloudiness (Fig. 8c).

Red segments of the flight path during flight 10 mark where the aircraft encountered the very dry uppertropospheric air, in very good correspondence with the operational analysis. The highest branches of the flight track correspond to the measurements during segments A and D. 
(a)

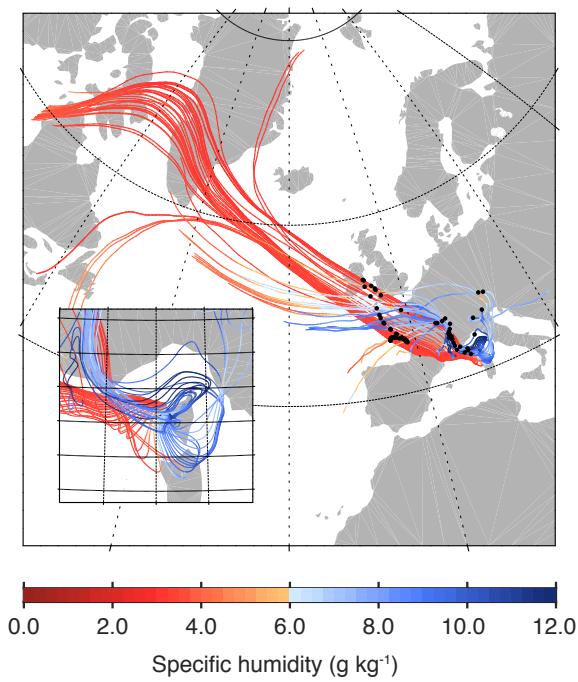

(b)

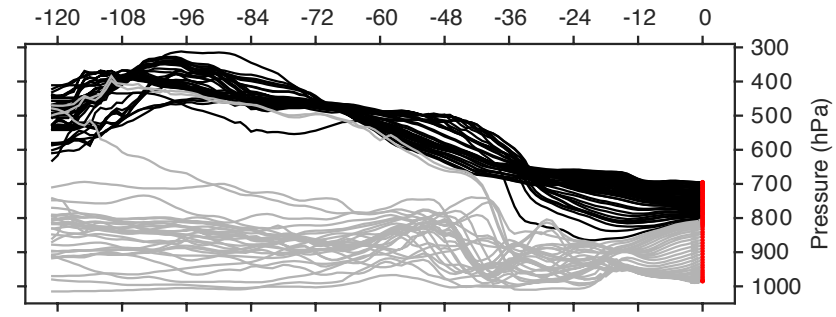

(c)

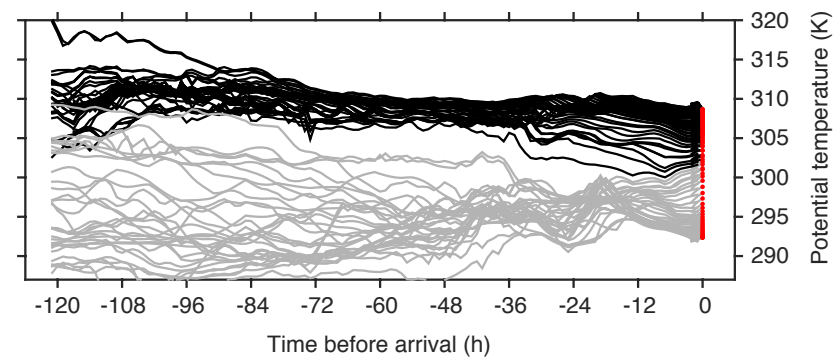

Figure 11. Backward trajectories for the downward leg of the second profile in segment D during flight 10 (21 September 2012, 07:5408:06 UTC). (a) Five-day trajectories coloured with specific humidity $\left(\mathrm{g} \mathrm{kg}^{-1}\right)$, with small inset showing a zoom around Corsica. Black dots indicate trajectory locations $48 \mathrm{~h}$ before measurement time. (b) Pressure in hectopascal and (c) potential temperature in kelvin along 5-day trajectories vs. time before measurement. Trajectories arriving with a humidity of less than $2 \mathrm{~g} \mathrm{~kg}^{-1}$ are shown in black, all others in grey. Time of aircraft encounter in panel (b) and (c) is marked by red dots.
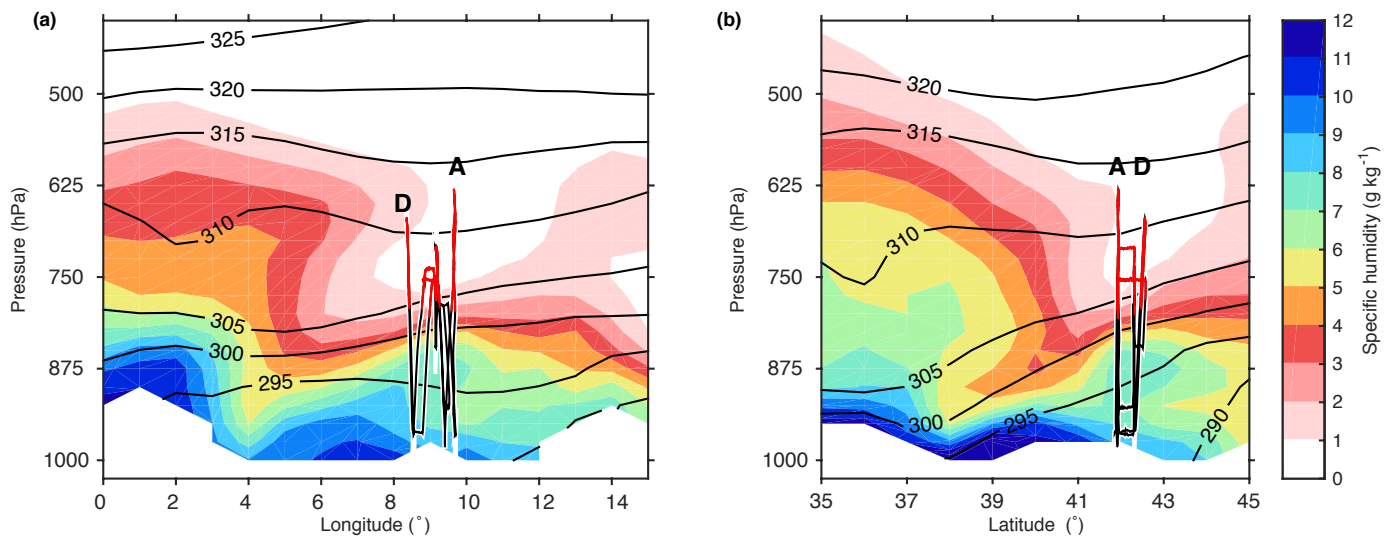

Figure 12. Vertical sections across Corsica during flight 10 (06:00 UTC, 21 September 2012): (a) from 0 to $15^{\circ} \mathrm{E}$ at $42^{\circ} \mathrm{N}$ and (b) from 35 to $45^{\circ} \mathrm{N}$ at $9^{\circ} \mathrm{E}$. Panels show specific humidity ( $\mathrm{g} \mathrm{kg}^{-1}$, shading), and potential temperature (K, black contours) from ECMWF operational analyses. The flight track for flight 10 is overlaid as a black line, with segments of specific humidity below $2 \mathrm{~g} \mathrm{~kg}^{-1} \mathrm{plotted} \mathrm{in} \mathrm{red.} \mathrm{A} \mathrm{and} \mathrm{D}$ correspond to the segments in Fig. 10.

The less dry conditions, but in particular also the lower depletion of the $\delta \mathrm{D}$ and $\delta^{18} \mathrm{O}$, indicate that the front of the advancing tropical air mass had been encountered during segment $\mathrm{D}$ (Fig. 12a), explaining the marked isotopic inversion between 2300 and $3500 \mathrm{~m}$ a.s.l. (Fig. 9g) as the result of the complex layering of air masses with very different water vapour transport histories.

\section{Summary and conclusions}

In summary, we present here results from an extensive airborne survey of the isotopic composition of water vapour above the western Mediterranean during HyMeX SOP1. The data set represents one of the first extensive, welldocumented airborne measurement campaigns of the isotopic composition lower troposphere since the 1970s with a high spatial and temporal resolution. During the 21 successful flights with 59 flight hours in total, several distinct weather situations were probed, yielding high day-to-day 
variability and often strong vertical and horizontal gradients in the stable isotope signals and confirming similar findings from another recent airborne study (Dyroff et al., 2015). In general, the spatial variability was much larger than anticipated from earlier low-resolution data, which causes challenges for remote-sensing observations of stable isotopes that have a low vertical resolution and for the comparison with model simulations that average over larger spatial regions than the aircraft measurements are representative of.

A sequence of flights performed in a situation of subsidence of upper- and middle-troposphere air over Corsica showed strong vertical gradients in the isotopic composition of water vapour, reaching up to $-25.4 \% 100 \mathrm{~m}^{-1}$ for $\delta \mathrm{D}$ across an inversion layer about $700 \mathrm{~m}$ thick. Mixing between the descending air mass and boundary-layer air influenced by evaporation appears as the dominant process responsible for the observed variability. Immediate, local stable isotope fractionation that could be described by a Rayleigh fractionation model, for example in dense, precipitating clouds, was not observed during the flights and must thus have taken place elsewhere in regions with saturated conditions beforehand. Obtaining this kind of information would not be possible from water vapour concentration measurements alone, which emphasizes the additional use of stable isotopes in studies of the atmospheric water cycle.

Our high-resolution measurements of d-excess clearly show that this second-order parameter adds information on the origin and processing of atmospheric water vapour. A careful design of the measurement installation and calibration routines is required to obtain interpretable data at a temporal resolution of 30-60 s and a spatial resolution of 2-4 km horizontally and $150-300 \mathrm{~m}$ vertically. High d-excess near the sea surface and above the boundary-layer inversion are contrasted with relatively low d-excess near the top of the boundary layer. These characteristics are consistent with the prevalence of non-equilibrium evaporation conditions near the sea surface and during evaporation of rain in unsaturated regions and cloud dissolution near the boundary-layer top. At high elevations, non-linearities in the delta scale may have contributed to high values of d-excess in highly depleted isotope conditions. Because of limitations of the instrumentation in low-humidity conditions, the remaining uncertainties call for further studies to confirm these findings. Nonetheless, the data reported here do demonstrate that the d-excess is a valuable, high-resolution process and source tracer for the meteorological situations encountered during the aircraft campaign.
The comprehensive data set of the stable isotope composition of atmospheric water vapour acquired together with many other observations during the HyMeX SOP1 (Ducrocq et al., 2014) can be further exploited for process studies using both the primary isotopes and the d-excess as well as for model evaluation. In the future, more extensive data sets for other regions on the atmospheric isotopic composition will be highly valuable in constraining the atmospheric water cycle in numerical weather and climate prediction models. Future campaigns would benefit in particular from complementary sampling, either ship-based or land-based, of the nearsurface water vapour in the evaporation region, providing further insight into the mixing between boundary layer and free troposphere.

Data availability. The data set of the water vapour stable isotope composition from this study is available from the HyMeX data base at http://mistrals.sedoo.fr/HyMeX/. The archived data set "Water vapour isotopes" (doi:10.6096/MISTRALS-HyMeX.1475) includes the calibrated isotope measurements and several basic flight parameters, all averaged at a $30 \mathrm{~s}$ time interval. Higher-resolution data can be obtained from the corresponding author on request. 


\section{Appendix A: Data and measurement details}

\section{A1 Measurement setup}

The high-frequency meteorological measurements (temperature, winds, pressure, humidity) onboard the D-IBUF were located inside the nose boom. The inlet for measuring stable isotopes in ambient water vapour was located at the top of the aircraft at $8.6 \mathrm{~m}$ distance (Fig. A1). A backward-facing short stainless steel pipe (1/4" O.D.) inside an aerodynamic housing was connected to PTFE tubing (1/4" O.D.) inside the aircraft (Fig. A2). Air was drawn through a $0.2 \mu \mathrm{m}$ PTFE membrane filter with $50 \mathrm{~mm}$ diameter (SLFG05010, Merck Millipore) and an inlet at $30 \mathrm{~L} \mathrm{~min}^{-1}$ under standard conditions using a bypass pump (ASF Thomas TF2). At a T-fitting connected to this inlet, the Picarro L2130-i extracted sample air from this air stream at $0.1 \mathrm{~L} \mathrm{~min}^{-1}$ using another pump (S2003, Picarro Inc.). Temperature in the non-pressurized cabin was not stabilized and the tubing inside the aircraft was not heated. Condensation was, however, unlikely as the cabin of the aircraft was generally warmer than air temperature outside the aircraft.

\section{A2 CRDS humidity calibration}

The correspondence between the CRDS humidity and the reference humidity allowed compensating for time shifts between the two measurements due to the inlet, piping, position in the aircraft, and computer clock differences. For each flight, the time shift (typically 4-7 s) was determined from the highest correlation between the two humidity measurements, shifted in $1 \mathrm{~s}$ intervals within moving $60 \mathrm{~s}$ windows. The correlation coefficient between both humidity measurements after time shift correction was $\rho>0.97$ at a $1 \mathrm{~Hz}$ averaging for all 21 flights. Humidity measurements from the CRDS were then calibrated with the HCLY humidity data using a linear fit determined from each individual flight at a $1 \mathrm{~Hz}$ time resolution. The offset of this linear fit was mostly stable between flights. The original bypass pump failed from flight 17 onward and was replaced with an identical pump before flight 28 . The offset of this linear fit was mostly stable between flights, whereas the slope changed slightly from 1.0 to about 1.1 after the installation of the replacement pump (not shown). This could affect the pressure in the inlet system, resulting in a different regulatory behaviour and pressure hysteresis of the measurement setup but not a change in flow rate. This may suggest that calibration procedures should ideally cover the entire inlet system, including the bypass pump.

\section{A3 Humidity dependency correction of the stable isotope parameters}

The humidity-isotope response correction that is required for all commercial water isotope spectrometers is known as a key element for reliable d-excess measurements (Tremoy et al.,

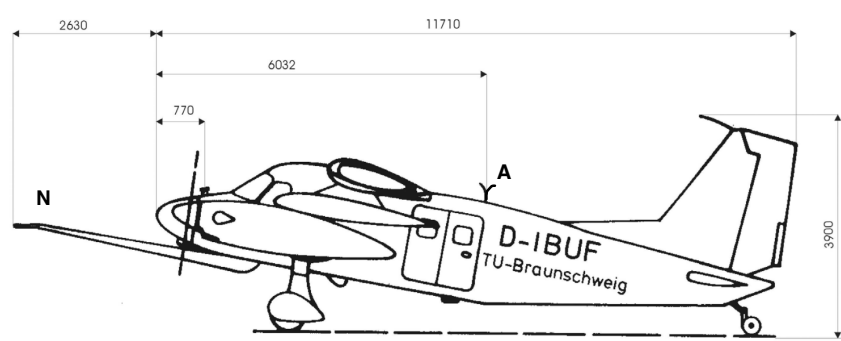

Figure A1. Location of the nose boom instrumentation $(\mathrm{N})$ and the inlet for the ambient air measurements (A) onboard the Dornier128 D-IBUF aircraft for the HyMeX measurement campaign. All dimensions in millimetres. Modified from Wieser (2005).

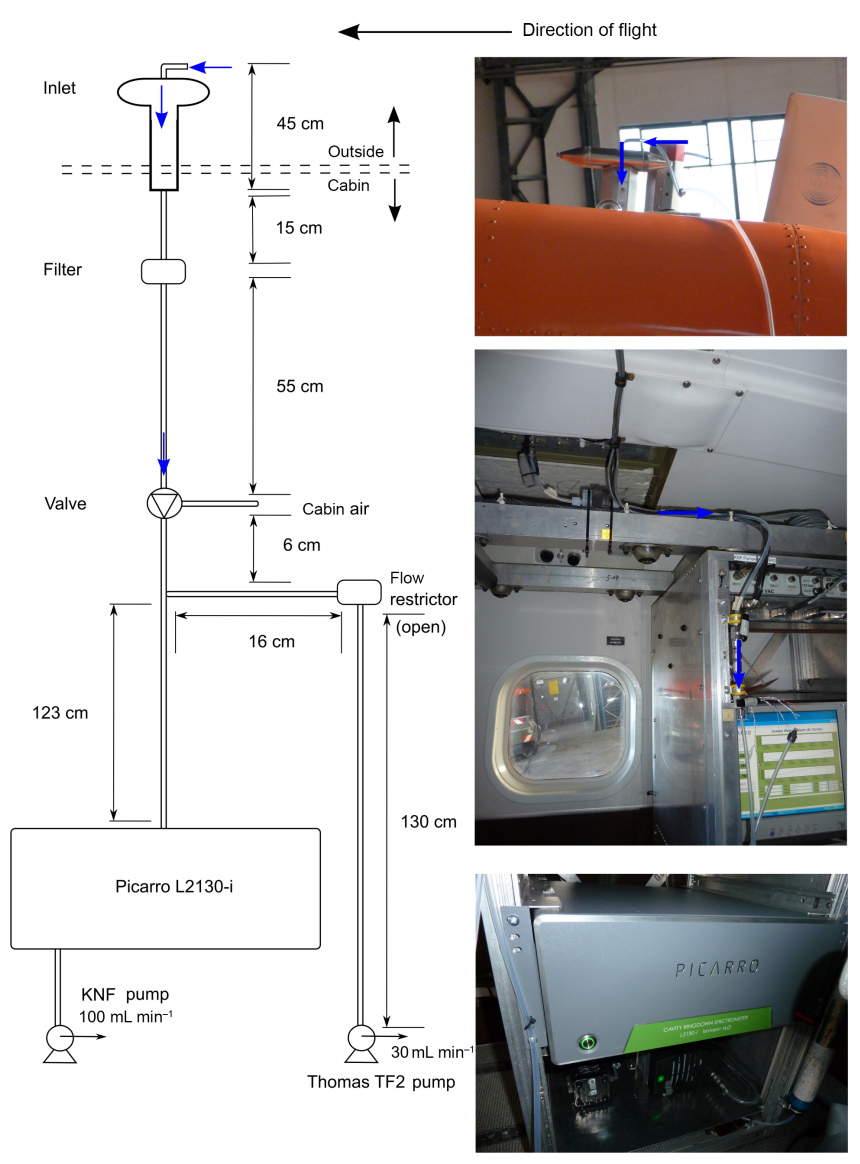

Figure A2. Setup of the Picarro L2130-i instrument onboard the Dornier-128 D-IBUF. The pipe connected to the inlet in the top right is not part of the inlet system. From Aemisegger (2013).

2012; Aemisegger et al., 2012). Airborne humidity measurements can have a large range, and instruments need to be calibrated for the humidity dependency across the entire range of measurement data points. Correction functions for the dependency of the isotope parameters were determined at different times during and after the field campaign. These functions are different for each particular analyser. For the instrument used during the HyMeX SOP1, the $\delta^{18} \mathrm{O}$ and $\delta \mathrm{D}$ increased 

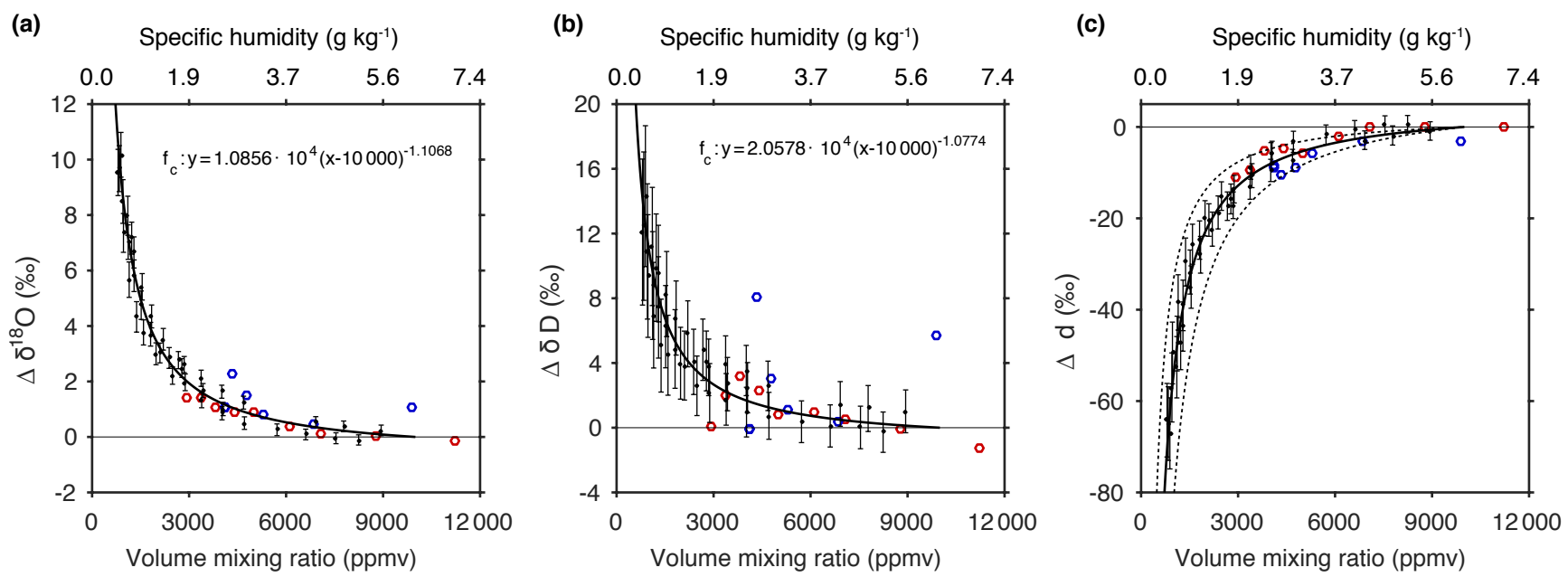

Figure A3. Correction functions of the isotopic composition as a function of the water concentration (volume mixing ratio in ppmv at bottom; specific humidity in $\mathrm{g} \mathrm{kg}^{-1}$ at top) determined during laboratory experiments after the field campaign for (a) $\delta^{18} \mathrm{O}$ and (b) $\delta \mathrm{D}$. (c) Effect on the d-excess when applying the correction to the primary stable isotope parameters. Blue and red preliminary data points were obtained in 2012 during and after the HyMeX field campaign; black data points are from an optimized laboratory setup in 2015. Vertical black bars show the standard deviation of each calibration point with measurements lasting for approximately 6-10 min. Correction function has been determined from a fit to the black data points only.

strongly for lower mixing ratios, resulting in a strong negative deviation of the d-excess. This calibration function was determined in the field on 26 September 2012 and immediately after the field campaign in a laboratory setup on 25 October 2012 and in a final optimized setup in the laboratory in August 2015. The correction functions and their impact on the d-excess are presented in Fig. A3. The humidity-isotope response correction varied only marginally within the range of measurement uncertainties, as shown by the data points from the two earlier calibration periods (red and blue circles). This suggests that mechanical stress during the flight did not have a strong influence on the humidity-isotope response correction function. All $\delta^{18} \mathrm{O}$ and $\delta \mathrm{D}$ data were corrected with Eqs. (1) and (2) at the highest time resolution before averaging according to the uncalibrated volume mixing ratio reported by the CRDS instrument.

\section{A4 Dependence of data quality on different factors}

As the number of absorbing water molecules decreases in the CRDS cavity with decreasing humidity, the precision of measurements decreases. The uncertainty of the measured sample depends on the ambient water vapour mixing ratio and can be estimated using calibration runs at different water vapour mixing ratios (Fig. A4). Depending on the flight and the water vapour mixing ratios the total uncertainty in $\delta \mathrm{D}$ is $\sim 1.8 \%$ o, $\sim 1.0 \%$ for $\delta^{18} \mathrm{O}$, and $\sim 10 \%$ ofor d. The precision of $\delta^{18} \mathrm{O}$ is approximately 5-6 times better than the precision of $\delta \mathrm{D}$. Temporal averaging then allows the retrieval of information at a better precision (Table 3).

Further influences on the data quality come from (i) uncertainty of the isotope-humidity response calibration,

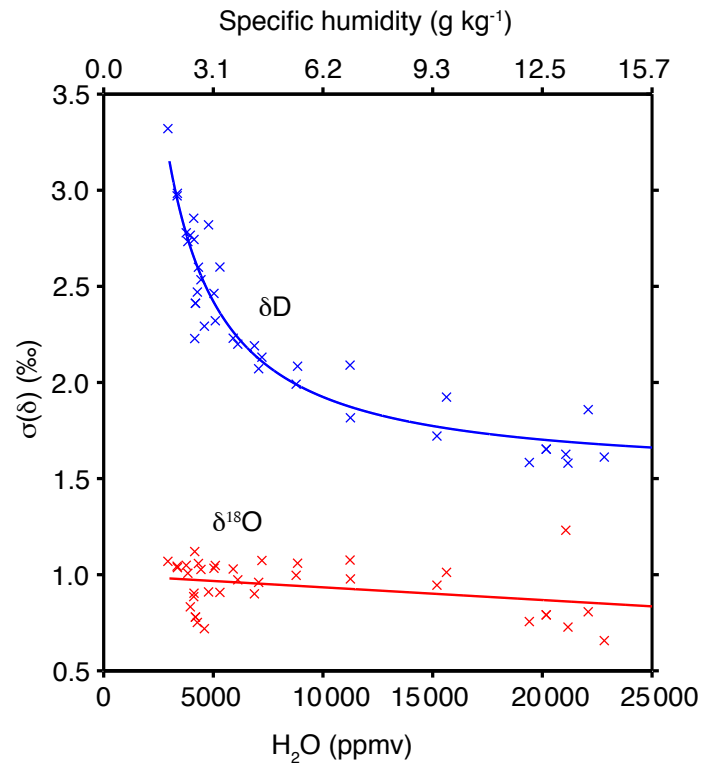

Figure A4. Standard deviation of calibration standard measurements in the field during the HyMeX campaign and in the laboratory after the campaign at different water vapour mixing ratios (experiments from 26 September and 25 October 2012).

(ii) larger drift of the measurement system due to mechanical stress during the flight, and (iii) memory effects of the inlet system. While the first aspect is covered in Sect. A3, the other two are briefly discussed here. The effect of enhanced mechanical stress during the flight can be approximately quantified from 4 days when calibrations at the same water concen- 
(a)

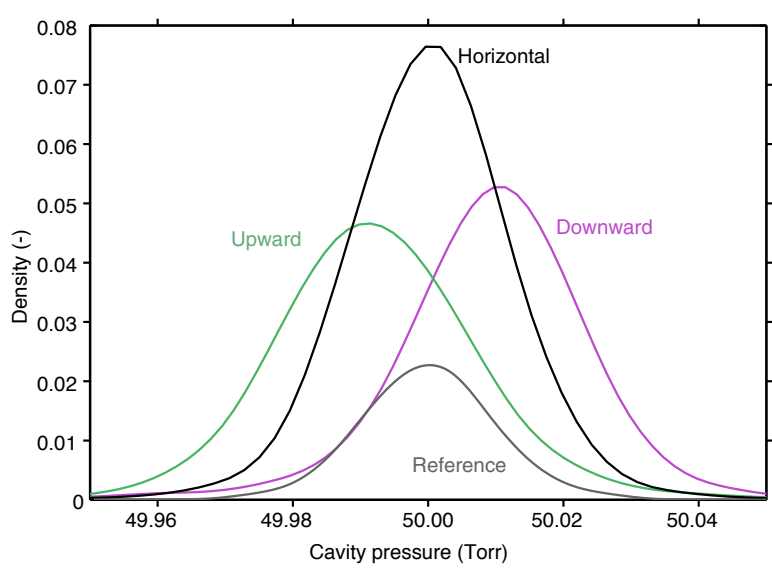

(b)

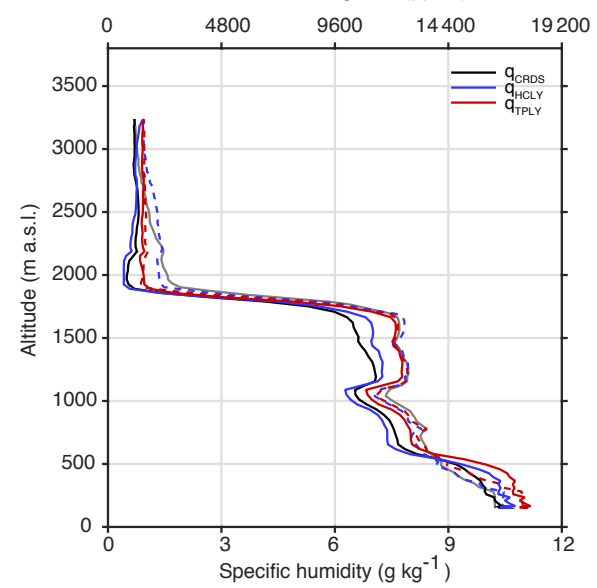

Figure A5. (a) Distributions of cavity pressure for flights 01-14 and 28-32 in purple for vertical velocities $<2 \mathrm{~m} \mathrm{~s}^{-1}$ (downward), in green for vertical velocities $>2 \mathrm{~m} \mathrm{~s}^{-1}$ (upward), and in black for horizontal legs with vertical velocities $2 \leq v \leq 2 \mathrm{~ms}^{-1}$. The distribution of the cavity pressure during a stability experiment (Allan test) in the hangar during the campaign (6 Oct 2012, 10:00-14:00 UTC) is shown in grey as a reference for stable measurement conditions. (b) Vertical profile of specific humidity during flight 10. Upward (dashed lines) and downward (solid lines) from three humidity products CRDS (black), HCLY (blue), and TPLY (red) are shown.

trations and with the same standards were available before and after the flight. Six bracketing calibrations were available at a volume mixing ratio of about $20000 \mathrm{ppmv}$ and two at about 4000 ppmv. Assuming linear drift between the calibrations, the overall drift was about $0.2 \% \mathrm{~h}^{-1}$ for $\delta^{18} \mathrm{O}$ and $0.5 \% \mathrm{~h}^{-1}$ for $\delta \mathrm{D}$. These numbers were independent of the stable isotope concentration. Drift was about 3 times stronger at 4000 ppmv based one set of bracketing calibrations only. Memory effects from the inlet system can become substantial during specific flight patterns, such as during vertical profiles across large humidity gradients (e.g. over $100 \mathrm{~s}$ when the humidity signal was spread out over $\sim 500 \mathrm{~m}$ during an upward profile; see Fig. 9). Wall effects of the PTFE tubing in the piping connecting the isotope analyser to the bypass inlet line at low humidity can disturb the isotope measurements for several minutes, instead of a response on the order of a few seconds when flying horizontal transects or profiles from low to high humidity layers. This is an aspect that is difficult to quantify in terms of data quality and affects only specific parts of the data set. Upward profiles in the data set should therefore be interpreted with particular care.

\section{A5 Pressure effects and hysteresis}

Aircraft data reported here were collected up to a pressure altitude of $580 \mathrm{hPa}$. Cavity pressure and temperatures inside the instrument are continuously stabilized, and records of these parameters indicate that no adjustment problems were encountered during most flight conditions. The instrument did, however, respond with a time lag to pressure changes inflicted by spiral descent, steep ascent, and turbulent vertical motions. The cavity pressure then deviates up to 0.02 Torr from its set value of 50 Torr (Fig. A5a). This offset is a result of the time delay of the regulating system when stabilizing the measurement conditions in the cavity during a pressure change. It could explain a part of the hysteresis seen in Fig. 9 in terms of both water vapour and isotopic composition. Interestingly, the d-excess profiles do not show a strong hysteresis effect, which could point towards compensation for the pressure changes when the d-excess is calculated. After an ascent or descent, the cavity almost immediately returns to the predefined measurement conditions. Herman et al. (2014) also observed a hysteresis of $\delta \mathrm{D}$ in their measurements and therefore only used downward profiles for satellite validation.

A shift in the linear fit between the water vapour mixing ratio from L2130-i and the D-IBUF fast response measurements (TPLY) can be observed for an upward flight when compared to a downward flight (Fig. A5b). Besides memory effects in the inlet system when moving from humid to dry air, possible causes of this hysteresis are slight shifts in the wavelength monitor or a widening of the absorption lines due to observed changes in the cavity pressure (Fig. A5a), which could also affect the isotope measurements. The shifts are small and the effect might be of a 1-2\%o magnitude. Nevertheless, this aspect should be kept in mind, when examining these profiles. It is not a priori clear how this affects the d-excess, but the good correspondence of upward and downward profiles of the d-excess indicate a small effect.

To exemplify the CRDS instrument performance during the flight, the cavity temperature, cavity pressure, and warmbox temperature are shown during the same transect as shown in Fig. 10, along with meteorological, stable isotope and flight track parameters in Fig. A6. After a warm-up phase following the power break before the start, the cavity tem- 

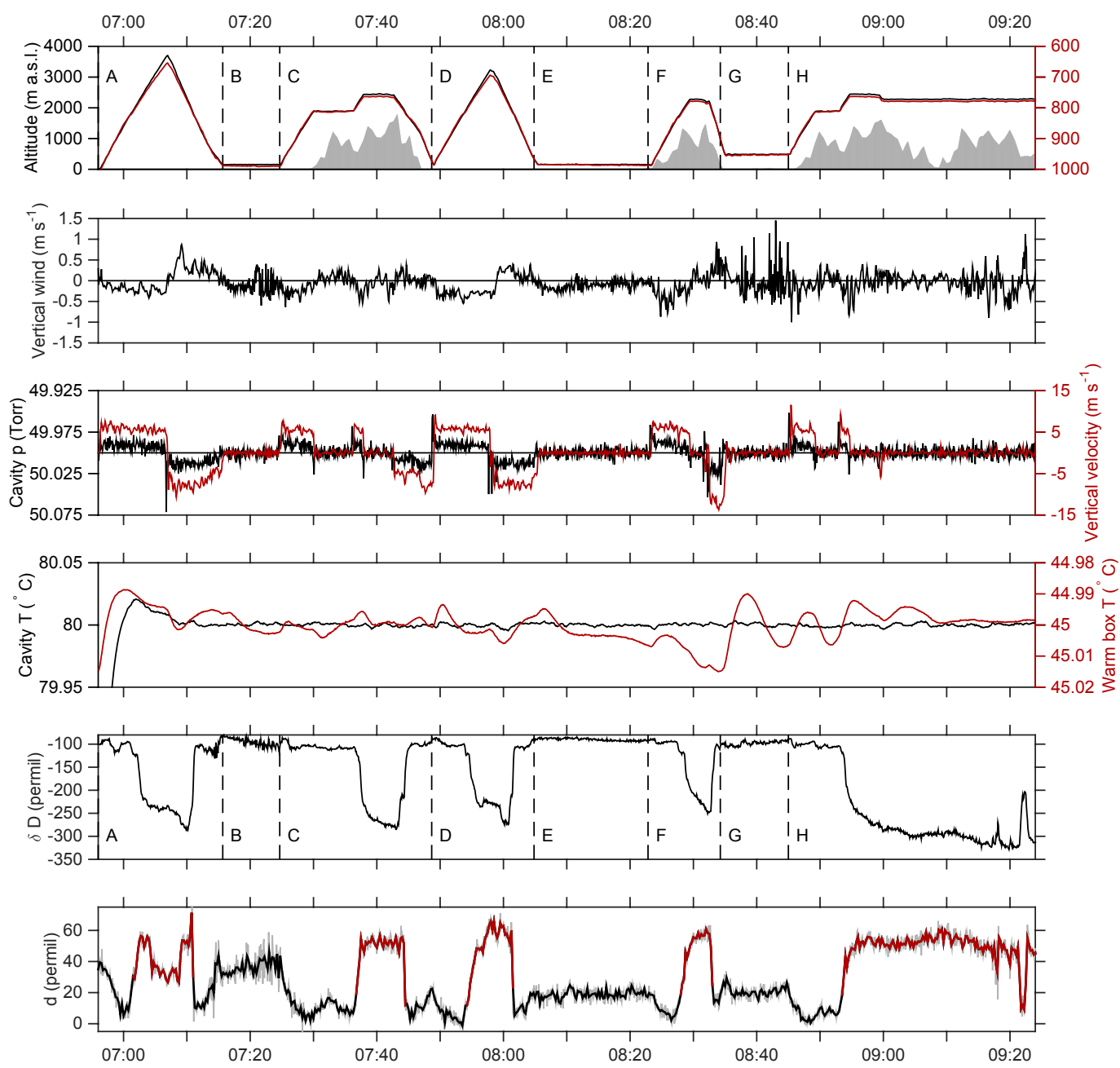

Figure A6. Instrument control parameters during segments A-H of flight 10 on 21 September 2012, 07:00-09:25 UTC. (a) Flight altitude (m a.s.l.; black), cabin pressure (hPa; red) and topography ( $\mathrm{m}$; grey shading); (b) vertical wind ( $\mathrm{m} \mathrm{s}^{-1}$ ); (c) CRDS cavity pressure (Torr; black) and vertical aircraft velocity $\left(\mathrm{m} \mathrm{s}^{-1}\right.$; red); (d) CRDS cavity temperature $\left({ }^{\circ} \mathrm{C}\right.$; black) and CRDS warm-box temperature $\left({ }^{\circ} \mathrm{C}\right.$; red); (e) $\delta \mathrm{D}$ (black line; \%o) at $15 \mathrm{~s}$ averaging time; (f) d-excess $(\%)$ at $15 \mathrm{~s}$ averaging time (grey line) and $30 \mathrm{~s}$ averaging time (black line). Sections highlighted in red are for specific humidity below $2 \mathrm{~g} \mathrm{~kg}^{-1}$.

perature and warm-box temperature stabilize during segment $A$ and remain narrowly within the required specifications throughout the flight. Cavity pressure, on the other hand, responds immediately to aircraft vertical velocity as expected from Fig. A6b. During a period of increased turbulence in segment $G$, vertical winds increase but do not show a visible impact on the instrument parameters. The isotope parameters $\delta \mathrm{D}$ and d-excess do not show clear indications of the cavity pressure changes, as the environmental signals are exceeding the effect of pressure changes substantially.

The calibration of the stable isotope measurements was routinely carried out before and after flights to test the stability of the instrument and to correct for a continuous drift of the wavelength monitor during the campaign. While calibration during the flight may be desirable to check that the instrument does not perform random jumps during the $3-4 \mathrm{~h}$ of flight time, the parallel measurement of water vapour $\left(\mathrm{H}_{2}^{16} \mathrm{O}\right)$ with other onboard instrumentation provides a valid control that the instrument did in fact remain stable during normal flight situations, while the calibrations bracketing several flights ensured the same for the isotope measurements. Calibration during the flight reduces the available measurement time and would be more relevant during long-term flights where instrument drift becomes substantial. In our case the improvement of the data quality due to in-flight calibration would have been relatively small (see Appendix A4). 
Competing interests. The authors declare that they have no conflict of interest.

Acknowledgements. We thank Kate Dennis (Picarro Inc.) for helpful support in operating the custom-modified water vapour stable isotope analyser. B. Adler (IMG-TRO) kindly helped extract the data from the energy balance station at San Giuliano, Corsica. Franziska Aemisegger was partly supported by a Swiss National Science Foundation (SNSF) grant (P2EZP2_155603). MeteoSwiss is gratefully acknowledged for access to the ECMWF analysis data. We thank the two anonymous reviewers for their detailed and constructive comments which helped to improve the paper.

Edited by: R. Holzinger

Reviewed by: three anonymous referees

\section{References}

Adler, B., Kalthoff, N., Kohler, M., Handwerker, J., Wieser, A., Corsmeier, U., Kottmeier, C., Lambert, D., and Bock, O.: The variability of water vapour and pre-convective conditions over the mountainous island of Corsica, Q. J. Roy. Meteor. Soc., 142, 335-346, doi:10.1002/qj.2545, 2015.

Aemisegger, F.: Atmospheric stable water isotope measurements at the timescale of extratropical weather systems, PhD thesis, ETH Zürich, Switzerland, 2013.

Aemisegger, F., Sturm, P., Graf, P., Sodemann, H., Pfahl, S., Knohl, A., and Wernli, H.: Measuring variations of $\delta^{18} \mathrm{O}$ and $\delta^{2} \mathrm{H}$ in atmospheric water vapour using two commercial laser-based spectrometers: an instrument characterisation study, Atmos. Meas. Tech., 5, 1491-1511, doi:10.5194/amt-5-1491-2012, 2012.

Aemisegger, F., Pfahl, S., Sodemann, H., Lehner, I., Seneviratne, S. I., and Wernli, H.: Deuterium excess as a proxy for continental moisture recycling and plant transpiration, Atmos. Chem. Phys., 14, 4029-4054, doi:10.5194/acp-14-4029-2014, 2014.

Aemisegger, F., Spiegel, J. K., Pfahl, S., Sodemann, H., Eugster, W., and Wernli, H.: Isotope meteorology of cold front passages: A case study combining observations and modeling, Geophys. Res. Lett., 42, 5652-5660, 2015.

Araguàs-Araguàs, L., Fröhlich, K., and Rozanski, K.: Deuterium and oxygen-18 isotope composition of precipitation and atmospheric moisture, Hydrol. Process., 14, 1341-1355, 2000.

Bailey, A., Noone, D., Berkelhammer, M., Steen-Larsen, H. C., and Sato, P.: The stability and calibration of water vapor isotope ratio measurements during long-term deployments, Atmos. Meas. Tech., 8, 4521-4538, doi:10.5194/amt-8-4521-2015, 2015.

Barthlott, C., Adler, B., Kalthoff, N., Handwerker, J., Kohler, M., and Wieser, A.: The role of Corsica in initiating nocturnal offshore convection, Q. J. Roy. Meteor. Soc., 142, 222-237, doi:10.1002/qj.2415, 2014.

Bastrikov, V., Steen-Larsen, H. C., Masson-Delmotte, V., Gribanov, K., Cattani, O., Jouzel, J., and Zakharov, V.: Continuous measurements of atmospheric water vapour isotopes in western Siberia (Kourovka), Atmos. Meas. Tech., 7, 1763-1776, doi:10.5194/amt-7-1763-2014, 2014.
Benetti, M., Reverdin, G., Pierre, C., Merlivat, L., Risi, C., SteenLarsen, H. C., and Vimeux, F.: Deuterium excess in marine water vapor: Dependency on relative humidity and surface wind speed during evaporation, J. Geophys. Res.-Atmos., 119, 584593, 2014.

Benetti, M., Aloisi, G., Reverdin, G., Risi, C., and Sèze, G.: Importance of boundary layermixing for the isotopic composition of surface vapor over the subtropical North Atlantic Ocean, J. Geophys. Res.-Atmos., 120, 2190-2209, 2015.

Coplen, T. B.: Guidelines and recommended terms for expression of stable-isotope-ratio and gas-ratio measurement results, Rapid Commun. Mass Sp., 25, 2538-2560, 2011.

Corsmeier, U., Hankers, R., and Wieser, A.: Airborne turbulence measurements in the lower troposphere onboard the research aircraft Dornier 128-6, D-IBUF, Meteorol. Z., 10, 315-329, 2001.

Dansgaard, W.: Stable isotopes in precipitation, Tellus, 16, 436468, 1964.

Drobinski, P., Ducrocq, V., Alpert, P., Anagnostou, E., Béranger, K., Borga, M., Braud, I., Chanzy, A., Davolio, S., Delrieu, G., Estournel, C., Boubrahmi, N. F., Font, J., Grubišić, V., Gualdi, S., Homar, V., Ivančan-Picek, B., Kottmeier, C., Kotroni, V., Lagouvardos, K., Lionello, P., Llasat, M. C., Ludwig, W., Lutoff, C., Mariotti, A., Richard, E., Romero, R., Rotunno, R., Roussot, O., Ruin, I., Somot, S., Taupier-Letage, I., Tintore, J., Uijlenhoet, R., and Wernli, H.: HyMeX: A 10-Year Multidisciplinary Program on the Mediterranean Water Cycle, B. Am. Meteorol. Soc., 95, 1063-1082, 2014.

Ducrocq, V., Braud, I., Davolio, S., Ferretti, R., Flamant, C., Jansa, A., Kalthoff, N., Richard, E., Taupier-Letage, I., Ayral, P.-A., Belamari, S., Berne, A., Borga, M., Boudevillain, B., Bock, O., Boichard, J.-L., Bouin, M.-N., Bousquet, O., Bouvier, C., Chiggiato, J., Cimini, D., Corsmeier, U., Coppola, L., Cocquerez, P., Defer, E., Delanoë, J., Di Girolamo, P., Doerenbecher, A., Drobinski, P., Dufournet, Y., Fourrié, N., Gourley, J. J., Labatut, L., Lambert, D., Le Coz, J., Marzano, F. S., Molinié, G., Montani, A., Nord, G., Nuret, M., Ramage, K., Rison, W., Roussot, O., Said, F., Schwarzenboeck, A., Testor, P., Van Baelen, J., Vincendon, B., Aran, M., Tamayo, J., Ducrocq, V., Braud, I., Davolio, S., Ferretti, R., Jansa, A., Richard, E., Taupier-Letage, I., Ayral, P.-A., Belamari, S., Berne, A., Borga, M., Boudevillain, B., Bock, O., Boichard, J.-L., Bouin, M.-N., Bousquet, O., Bouvier, C., Chiggiato, J., Cimini, D., Corsmeier, U., Coppola, L., Cocquerez, P., Defer, E., Delanoë, J., Di Girolamo, P., Doerenbecher, A., Drobinski, P., Dufournet, Y., Fourrié, N., Gourley, J. J., Labatut, L., Lambert, D., Le Coz, J., Marzano, F. S., Molinié, G., Montani, A., Nord, G., Nuret, M., Ramage, K., Rison, W., Roussot, O., Said, F., Schwarzenboeck, A., Testor, P., Van Baelen, J., Vincendon, B., Aran, M., and Tamayo, J.: HyMeX-SOP1: The Field Campaign Dedicated to Heavy Precipitation and Flash Flooding in the Northwestern Mediterranean, B. Am. Meteorol. Soc., 95, 1083-1100, doi:10.1175/BAMS-D12-00244.1, 2014.

Dyroff, C., Fütterer, D., and Zahn, A.: Compact diode-laser spectrometer ISOWAT for highly sensitive airborne measurements of water-isotope ratios, Appl. Phys. B-Lasers O., 98, 537-548, 2010.

Dyroff, C., Sanati, S., Christner, E., Zahn, A., Balzer, M., Bouquet, H., McManus, J. B., González-Ramos, Y., and Schneider, M.: Airborne in situ vertical profiling of HDO $/ \mathrm{H}_{2}^{16} \mathrm{O}$ in the subtrop- 
ical troposphere during the MUSICA remote sensing validation campaign, Atmos. Meas. Tech., 8, 2037-2049, doi:10.5194/amt8-2037-2015, 2015.

Ehhalt, D. H.: Vertical profiles of HTO, HDO, and H2O in the troposphere, National Center for Atmospheric Research, Boulder, Colorado, 1974.

Ehhalt, D. H. and Östlund, H. G.: Deuterium in Hurricane Faith 1966: Preliminary results, J. Geophys. Res., 75, 2323-2327, doi:10.1029/JC075i012p02323, 1970.

Ehhalt, D. H., Rohrer, F., and Fried, A.: Vertical profiles of $\mathrm{HDO} / \mathrm{H}_{2} \mathrm{O}$ in the troposphere, J. Geophys. Res., 110, D13301, doi:10.1029/2004JD005569, 2005.

Galewsky, J., Rella, C., Sharp, Z., Samuels, K., and Ward, D.: Surface measurements of upper tropospheric water vapor isotopic composition on the Chajnantor Plateau, Chile, Geophys. Res. Lett., L17803, doi:10.1029/2011GL048557, 2011.

Gat, J. R.: Oxygen and hydrogen isotopes in the hydrologic cycle, Annu. Rev. Earth Pl. Sc., 24, 225-262, 1996.

Gat, J. R.: Atmospheric water balance - the isotopic perspective, Hydrol. Process., 14, 1357-1369, 2000.

Gat, J. R., Klein, B., Kushnir, Y., Roether, W., Wernli, H., Yam, R., and Shemesh, A.: Isotope composition of air moisture over the Mediterranean Sea: an index of air-sea interaction pattern, Tellus B, 55, 953-965, 2003.

Gedzelman, S. D.: Deuterium in water vapour above the atmospheric boundary layer, Tellus B, 40, 134-147, 1988.

Hanisco, T. F., Moyer, E. J., Weinstock, E. M., St Clair, J. M., Sayres, D. S., Smith, J. B., Lockwood, R., Anderson, J. G., Dessler, A. E., Keutsch, F. N., Spackman, J. R., Read, W. G., and Bui, T. P.: Observations of deep convective influence on stratospheric water vapor and its isotopic composition, Geophys. Res. Lett., 34, L04814, doi:10.1029/2006GL027899, 2007.

$\mathrm{He}, \mathrm{H}$. and Smith, R.: Stable isotope composition of water vapor in the atmospheric boundary layer above the forests of New England, J. Geophys. Res., 104, 11657-11673, 1999.

Herman, R. L., Cherry, J. E., Young, J., Welker, J. M., Noone, D., Kulawik, S. S., and Worden, J.: Aircraft validation of Aura Tropospheric Emission Spectrometer retrievals of $\mathrm{HDO} / \mathrm{H}_{2} \mathrm{O}$, Atmos. Meas. Tech., 7, 3127-3138, doi:10.5194/amt-7-3127-2014, 2014.

IAEA: Reference Sheet for VSMOW2 and SLAP2 International Measurement Standards, International Atomic Energy Agency, Vienna, 5 pp., 2009.

Iannone, R. Q., Kassi, S., Jost, H.-J., Chenevier, M., Romanini, D., Meijer, H. A. J., Dhaniyala, S., Snels, M., and Kerstel, E. R. T.: Development and airborne operation of a compact water isotope ratio infrared spectrometer, Isot. Environ. Health S., 45, 303320, 2009.

Jouzel, J., Alley, R. B., Cuffey, K. M., Dansgaard, W., Grootes, P., Hoffmann, G., Johnsen, S. J., Koster, R. D., Peel, D., Shuman, C. A., Stievenard, M., Stuiver, M., and White, J.: Validity of the temperature reconstruction from water isotopes in ice cores, J. Geophys. Res., 102, 26471-26487, 1997.

Kalthoff, N., Adler, B., Wieser, A., Kohler, M., Träumner, K., Handwerker, J., Corsmeier, U., Khodayar, S., Lambert, D., Kopmann, A., Kunka, N., Dick, G., Ramatschi, M., Wickert, J., and Kottmeier, C.: KITcube - a mobile observation platform for convection studies deployed during HyMeX, Meteorol. Z., 22, 633647, 2013.
Kerstel, E. R. T.: Isotope ratio infrared spectrometry, in: Handbook of Stable Isotope Analytical Techniques, edited by: de Groot, P. A., 759-787, Elsevier, Amsterdam, 2004.

Kurita, N.: Origin of Arctic water vapor during the ice-growth season, Geophys. Res. Lett., 38, L02709, doi:10.1029/2010GL046064, 2011.

Lawrence, J. R., Gedzelman, S. D., Gamache, J., and Black, M.: Stable isotope ratios: Hurrican Olivia, J. Atmos. Chem., 41, 6782, 2002.

Merlivat, L. and Jouzel, J.: Global climatic interpretation of the Deuterium-Oxygen 18 relationship for precipitation, J. Geophys. Res., 84, 5029-5033, 1979.

Noone, D.: Pairing measurements of the water vapor isotope ratio with humidity to deduce atmospheric moistening and dehydration in the Tropical Midtroposphere, J. Climate, 25, 4476-4494, 2012.

Pfahl, S. and Sodemann, H.: What controls deuterium excess in global precipitation?, Clim. Past, 10, 771-781, doi:10.5194/cp10-771-2014, 2014.

Pfahl, S. and Wernli, H.: Air parcel trajectory analysis of stable isotopes in water vapor in the eastern Mediterranean, J. Geophys. Res., 113, D20104, doi:10.1029/2008JD009839, 2008.

Pollock, W., Heidt, L. E., Lueb, R., and Ehhalt, D. H.: Measurement of Stratospheric Water-Vapor by Cryogenic Collection, J. Geophys. Res., 85, 5555-5568, 1980.

Risi, C., Noone, D., Worden, J., Frankenberg, C., Stiller, G., Kiefer, M., Funke, B., Walker, K., Bernath, P., Schneider, M., Wunch, D., Sherlock, V., Deutscher, N., Griffith, D., Wennberg, P. O., Strong, K., Smale, D., Mahieu, E., Barthlott, S., Hase, F., García, O., Notholt, J., Warneke, T., Toon, G., Sayres, D., Bony, S., Lee, J., Brown, D., Uemura, R., and Sturm, C.: Processevaluation of tropospheric humidity simulated by general circulation models using water vapor isotopologues: 1 . Comparison between models and observations, J. Geophys. Res., 117, D05303, doi:10.1029/2011jd016621, 2012.

Rozanski, K. and Sonntag, C.: Vertical distribution of deuterium in atmospheric water vapour, Tellus, 34, 135-141, 1982.

Rozanski, K. and Sonntag, C.: Reply to C. B. Taylor, Tellus B, 36, 71-72, doi:10.1111/j.1600-0889.1984.tb00054.x, 1984.

Samuels-Crow, K. E., Galewsky, J., Sharp, Z. D., and Dennis, K. J.: Deuterium excess in subtropical free troposphere water vapor: Continuous measurements from the Chajnantor Plateau, northern Chile, Geophys. Res. Lett., 41, 8652-8659, doi:10.1002/2014GL062302, 2014.

Sayres, D. S., Moyer, E. J., Hanisco, T. F., Clair, J. M. S., Keutsch, F. N., O’Brien, A., Allen, N. T., Lapson, L., Demusz, J. N., Rivero, M., Martin, T., Greenberg, M., Tuozzolo, C., Engel, G. S., Kroll, J. H., Paul, J. B., and Anderson, J. G.: A new cavity based absorption instrument for detection of water isotopologues in the upper troposphere and lower stratosphere, Rev. Sci. Instrum., 80, 044102, doi:10.1063/1.3117349, 2009.

Smith, R. B.: Deuterium in North Atlantic storm tops, J. Atmos. Sci., 49, 2041-2057, 1992.

Sodemann, H., Masson-Delmotte, V., Schwierz, C., Vinther, B., and Wernli, H.: Interannual variability of Greenland winter precipitation sources. 2. Effects of North Atlantic Oscillation variability on stable isotopes in precipitation, J. Geophys. Res., 113, D12111, doi:10.1029/2007JD009416, 2008a. 
Sodemann, H., Schwierz, C., and Wernli, H.: Interannual variability of Greenland winter precipitation sources: Lagrangian moisture diagnostic and North Atlantic Oscillation influence, J. Geophys. Res., 113, D03107, doi:10.1029/2007JD008503 2008b.

Sonntag, C., Münnich, K. O., Jacob, H., and Rozanski, K.: Variations of deuterium and oxygen-18 in continental precipitation and groundwater, and their causes, in: Variations in the Global Water Budget, edited by: Street-Perrott, A., Beran, M., and Ratcliffe, R., Springer Netherlands, 107-124, doi:10.1007/978-94009-6954-4_7, 1983.

Sturm, P. and Knohl, A.: Water vapor $\delta^{2} \mathrm{H}$ and $\delta^{18} \mathrm{O}$ measurements using off-axis integrated cavity output spectroscopy, Atmos. Meas. Tech., 3, 67-77, doi:10.5194/amt-3-67-2010, 2010.

Taylor, C. B.: The vertical variations of isotopic concentrations of tropospheric water vapour over continental Europe, and their relationship to tropospheric structure, $\mathrm{PhD}$ thesis, Institute of $\mathrm{Nu}$ clear Sciences, Lower Hutt, New Zealand, 1972.

Taylor, C. B.: Vertical-distribution of deuterium in atmospheric water-vapor: problems in application to assess atmospheric condensation models, Tellus B, 36, 67-70, 1984.

Tremoy, G., Vimeux, F., Mayaki, S., Souley, I., Cattani, O., Risi, C., Favreau, G., and Oi, M.: A 1-year long $\delta^{18} \mathrm{O}$ record of water vapor in Niamey (Niger) reveals insightful atmospheric processes at different timescales, Geophys. Res. Lett., 39, L08805, doi:10.1029/2012GL051298, 2012.
Tsujimura, M., Sasaki, L., Yamanaka, T., Sugimoto, A., Li, S.-G., Matsushima, D., Kotani, A., and Saandar, M.: Vertical distribution of stable isotopic composition in atmospheric water vapor and subsurface water in grassland and forest sites, eastern Mongolia, J. Hydrol., 333, 35-46, 2007.

Uemura, R., Masson-Delmotte, V., Jouzel, J., Landais, A., Motoyama, H., and Stenni, B.: Ranges of moisture-source temperature estimated from Antarctic ice cores stable isotope records over glacial-interglacial cycles, Clim. Past, 8, 11091125, doi:10.5194/cp-8-1109-2012, 2012.

Webster, C. R. and Heymsfield, A. J.: Water isotope ratios D/H, ${ }^{18} \mathrm{O} /{ }^{16} \mathrm{O},{ }^{17} \mathrm{O} /{ }^{16} \mathrm{O}$ in and out of clouds map dehydration pathways, Science, 302, 1742-1745, 2003.

Wernli, H. and Davies, H. C.: A Lagrangian-based analysis of extratropical cyclones. I: The method and some applications, Q. J Roy. Meteor. Soc., 123, 467-489, 1997.

Wieser, A.: Messung turbulenter Spurengasflüsse vom Flugzeug aus, $\mathrm{PhD}$ thesis, University of Karlsruhe, Germany, Wissenschaftliche Berichte des Instituts für Meteorologie und Klimaforschung, Nr. 34, 2005.

Worden, J., Noone, D., Bowman, K., and the TES team: Importance of rain evaporation and continental convection in the tropical water cycle, Nature, 445, 528-532, 2007.

Zahn, A., Barth, V., Pfeilsticker, K., and Platt, U.: Deuterium, oxygen-18, and tritium as tracers for water vapour transport in the lower stratosphere and tropopause region, J. Atmos. Chem., 30, 25-47, 1998. 